\title{
LA DOCENCIA EN LENGUA INGLESA EN LOS PLANES DE ESTUDIO UNIVERSITARIO: REVISIÓN JURÍDICO-NORMATIVA DE SU IMPLEMENTACIÓN EN EL GRADO EN DERECHO DE LA UNIVERSIDAD DE MÁLAGA Y APUNTES PARA CONFIGURAR LA ASIGNATURA DERECHO DEL TRABAJO Y DE LA SEGURIDAD SOCIAL
}

English as a medium of instruction in university study plans: legal-regulatory review of its implementation in the Degree in Law at the University of Malaga and notes to configure the subject Labor Law and Social Security

Recibido: 14 de diciembre de 2020

Aceptado: 13 de enero de 2021

María Salas Porras

Depto. Derecho del Trabajo y de la Seguridad Social

mariasalas@uma.es

Universidad de Málaga

\section{RESUMEN}

El trabajo que de seguida se presenta, a la postre busca ofrecer un ejemplo práctico de la implementación de docencia en lengua inglesa en una concreta asignatura, la que tiene como finalidad acercar el Derecho del Trabajo y la Seguridad Social a los alumnos del Grado en Derecho.

La circunscripción obligatoria al Plan de Estudios que ampara el diseño del programa de la citada asignatura justifica que hayamos hecho referencia a una específica realidad, la de la Universidad de Málaga, si bien la explicación teórico-jurídica de la introducción del inglés como lengua vehicular en la docencia universitaria española, bien podría ser exportable a cualquier otra Universidad pública de nuestro país.

\section{PALABRAS CLAVE}

inglés como lengua vehicular, derecho del trabajo y la seguridad social, grado en derecho, universidad de málaga.

\begin{abstract}
This paper ultimately seeks to offer a practical example of the implementation of teaching in English in a specific subject, which aims to bring Labor Law and Social Security closer to students of the Degree in Law.

The compulsory circumscription of the Study Plan that covers the design of the program of the aforementioned subject justifies that we have made reference to a specific reality, that of the University of Malaga, although the theoretical-legal explanation of the introduction of English as a vehicular language in Spanish university could well be exportable to any other public university in our country.
\end{abstract}

\section{KEYWORDS}

english as a medium of instruction, labor law and social security, law degree, university of málaga. 
Sumario: 1. Introducción. 2. El Espacio Europeo de Educación Superior: otro proceso de convergencia comunitaria en que la competencia lingüística es crucial. 3. La adaptación de la titulación en Derecho al proceso de convergencia del EEES. 3.1. La docencia en lengua extranjera de asignaturas de contenido jurídico y su introducción en los planes de estudio de la Universidad de Málaga: especial atención al Grado en Derecho. 3.2. La transversalidad del bilingüismo: la acreditación del conocimiento de idioma distinto al castellano y la oferta educativa universitaria en segunda lengua. 4. Propuesta para la asignatura Derecho del Trabajo y la Seguridad Social del Grado en Derecho. Su diseño a partir de dos postulados. 4.1. Apostar de forma equilibrada por el valor de uso y por el valor de cambio del conocimiento. 4.2. Hacer de la imposición del inglés una oportunidad inclusiva a partir del aprendizaje constructivista. 4.3. Labor Law and Social Security from the perspective of the Spanish Legal System. 5. Bibliografía. 6. Anexo I (Propuesta de cronograma).

\section{Introducción.}

La docencia en la Universidad pública a través de lengua distinta del castellano -o de las cooficiales- es una realidad de reciente aparición cuya observancia, al menos por los docentes de las disciplinas jurídicas, dista de lo pingüe.

Esas parquedades justificarían, si bien sólo parcialmente, que hayamos dedicado el estudio a aproximarnos a este ámbito de la docencia universitaria, estando complementados nuestros motivos por habernos embarcados ya en este viaje y desear referir nuestras propias aportaciones; las cuales -esperamos- sirvan a otros que se aventuren en este mismo itinerario.

La estructura, pues, del ensayo se configura refiriendo de forma apriorística y con finalidad puramente introductoria -puesto que su debate y reflexión ha sido objeto de innumerables trabajos sobre cuyas conclusiones este se asienta- algunas cuestiones relativas al proceso de convergencia hacia el Espacio Europeo de Educación Superior, ampliamente conocido como Plan Bolonia, puesto que de él se derivan consecuencias tanto para la actual configuración del Plan de Estudios del Grado en Derecho aprobado por la Universidad de Málaga en que prestamos servicios, para el diseño del procedimiento de aprendizaje que ha de seguirse por el área de Derecho del Trabajo y de la Seguridad Social, así como para la propuesta que presentamos. Precisamente, la especialidad que plantea su formulación a partir de la docencia en idioma distinto al español, concretamente en lengua inglesa, resulta ampliamente influenciado por aquel proceso de convergencia dado que es el idioma -amén de la idiosincrasia de los pueblos- el único elemento físico que impide a los países miembros de la Unión Europea una convergencia mayor ${ }^{1}$.

2. El Espacio Europeo de Educación Superior: otro proceso de convergencia comunitaria en que la competencia linguíística es crucial.

La aprobación del Tratado de Maastricht en 1992 y la elevación a libertades de las necesidades más acuciantes para la construcción de un verdadero Mercado Único Europeo -la de circulación de capitales, bienes, servicios y personas- habían sido otro paso más en

\footnotetext{
${ }^{1}$ La discusión acerca de las ventajas y desventajas de esta convergencia no corresponde ser incluida en este trabajo dedicado a la propuesta docente de una concreta asignatura, empero tampoco queremos desconocer su importancia. Por ello remitimos al lector interesado en adentrarse en tales lides al ensayo de Joseph H. H. Weiler: The Constitution of Europe: Do the New Clothes Have an Emperor? Cambridge University Press, 1999 y, en versión inglesa, al de Jürgen Habermas: The Lure of Technocracy, Polity Press, Londres, 2015.
} 
la imparable dinámica convergente en que la Comunidad europea se había erigido ${ }^{2}$. Sin embargo, para estos momentos, en la década de los años noventa, el motor de la construcción europea necesitaba más combustible y la educación, desde hacía años, era -lo es, todavía- un ámbito por conquistar.

Cierto es que los padres fundadores no habían alcanzado a imaginar siquiera hasta dónde llegaría la incipiente realidad que apenas se consolidaba durante la posguerra del Segundo Gran Conflicto Bélico Mundial, empero, la realidad tras cuarenta años de rodaje demostraba que era posible, a partir de unos ideales de perdón, respeto y cooperación, alcanzar cotas insospechadas de paz y estabilidad socioeconómica.

En este contexto, decimos, el 25 de mayo de 1998, los Ministros de Educación de Francia, Alemania, Italia y Reino Unido firmaron en la Sorbona una Declaración instando al desarrollo de un "Espacio Europeo de Educación Superior" (EEES, en adelante) que, de conformidad con el artículo 126 del Tratado de Maastricht -actual 165 TFUE- diera cumplimiento a la competencia comunitaria reconocida en el ámbito educativo que limitaba su contribución al desarrollo de la educación de calidad a partir del fomento de la cooperación, lo cual se materializa, entre otras actuaciones, en el desarrollo de la dimensión europea en la enseñanza y en favorecer la movilidad de estudiantes y profesores. Es a partir de esa declaración que se reconoció la importancia de someter los sistemas de educación nacionales -especialmente en los niveles superiores- a un proceso de aproximación parecido al que existía para el reconocimiento de cualificaciones profesionales, si bien con las diferencias que la ut supra limitada competencia a nivel europeo podría conllevar. Fruto de aquella reunión surgió la Declaración de Bolonia de 1999 -documento político que contó con la suscripción de 29 Estados europeos e inició el Proceso de Bolonia-, siendo su finalidad primordial introducir un sistema más comparable, compatible y coherente para la educación superior europea. Esta otra Declaración sentó las bases para la construcción de un Espacio de Educación Superior ordenado conforme a los principios del incremento de la calidad, la movilidad, la diversidad, la competitividad y, orientado hacia la consecución, entre otros, de dos objetivos estratégicos: el incremento del empleo en la Unión Europea y la conversión del sistema Europeo de Formación Superior en un polo de atracción del conocimiento para estudiantes y profesores de otras partes del mundo. De ahí que en la actualidad puedan hallarse referencias al EEES en la Estrategia Europa $2020^{3}$-como se sabe denominación empleada para referirse a la configuración conjunta de las orientaciones de política económica y de empleo- y en el Marco Estratégico para la cooperación europea en el ámbito de la educación y la formación (ET 2020) ${ }^{4}$ cuyos cuatro objetivos comunes

\footnotetext{
${ }^{2}$ Nos tomamos el atrevimiento de citar aquí un ensayo nuestro publicado por la editorial Thomson Reuters Aranzadi en el año 2019 que, bajo la rúbrica Las libertades de Circulación y Establecimiento de Trabajadores. Aportaciones para el Avance de la Dimensión Social Europea desde el Enfoque Transnacional, pone de manifiesto, precisamente, esta reflexión en la página 27.

${ }^{3}$ Publicada como Comunicación de la Comisión Europea en el documento COM(2010) 2020 final y disponible en la web https://eur-lex.europa.eu/legal-content/ES/TXT/?uri=celex:52010DC2020, último acceso a fecha de 17/07/2020.

${ }^{4}$ También apoya el cumplimiento de los siguientes valores de referencia en toda Europa -alcanzables en este año 2020- a partir de la integración de al menos el 95\% de los niños en la educación preescolar, la reducción a menos del 15\% del porcentaje de jóvenes de 15 años con aptitudes insuficientes en lectura, matemáticas y ciencias, la reducción por debajo del 10\% del porcentaje de abandono de los estudios o la formación entre 18 y 24 años, como mínimo un $40 \%$ de la población de entre 30 y 34 años debe haber terminado alguna forma de educación superior, como mínimo un $15 \%$ de la población adulta debe participar en actividades de formación, al menos el 20\% de los titulados superiores y el $6 \%$ de los jóvenes de entre 18 y 34 años con un título de formación profesional inicial debe haber cursado algún periodo de estudios o formación en el extranjero, al menos el $82 \%$ de los titulados (personas de entre 20 y 34 años que han terminado al menos el
} 
aluden a hacer una realidad del aprendizaje permanente y de la movilidad, a mejorar la calidad y eficacia de la educación y la formación, a fomentar la igualdad, la cohesión social y la ciudadanía activa y, finalmente, a incrementar la creatividad y la innovación, incluido el emprendimiento, en todos los niveles de la educación y la formación.

El proceso de Bolonia, por tanto, se diseña como otro mecanismo más para facilitar el diálogo entre instituciones nacionales -en concreto los sistemas educativos- y se impulsa a través de conferencias bianuales de los Ministros de Educación preparadas por el Grupo de Seguimiento de Bolonia. En cada una de ellas se realiza un balance de lo conseguido hasta ese momento y se fijan nuevos objetivos para la siguiente cumbre ${ }^{5}$. La implantación oficial del EEES -que tuvo lugar en 2010 a partir de las Conferencias de Budapest y Viena- marca el final de la primera década del Proceso de Bolonia y la presentación oficial del EEES. Son muchas las críticas que hasta ese momento se habían vertido hacia el sistema, y por ello, las Declaraciones mencionadas tratan de buscar soluciones a partir del compromiso para impulsar una mayor movilidad de estudiantes y profesores, mejorar la enseñanza y el aprendizaje, promover la inserción laboral de los graduados. Objetivos estos que configuran la agenda para la próxima década de convivencia europea y que aparece recogida en el Marco Estratégico 2020 antes mentado.

Consciente la Unión Europea de que la implementación del EEES no iba a ser tarea fácil -tanto por el lado burocrático como por la parte relativa a la indirecta, pero existente, cesión de soberanía nacional- ha articulado una interesante partida económica que revierte directamente sobre las Universidades públicas y privadas de los Estados miembros. Su cuantía asciende al 3\% PIB de la Unión Europea y su objetivo es aumentar la inversión en investigación de base universitaria en un plazo de diez años contados a partir de aquel en que se aprobó el instrumento previsor: la Comunicación de la Comisión al Consejo y al Parlamento Europeo titulada "Cumplir la Agenda de Modernización para las Universidades: Educación, Investigación e Innovación”. Este documento que vio la luz el diez de mayo del año 2006 establecía, como no podría ser de otro modo y siempre bajo la

segundo ciclo de enseñanza secundaria) debe tener un empleo en un plazo de no más de tres años después de terminar los estudios.

Por otra parte, el marco se aplica por medio de toda una serie de herramientas e instrumentos tales como los grupos de trabajo compuestos por expertos nombrados por los Estados miembros y las principales partes interesadas, las actividades de aprendizaje entre iguales organizadas por un Estado miembro para dar a conocer buenas prácticas que se aplican en su territorio o estudiar un problema concreto con otros Estados miembros, las revisiones inter pares, en las que un grupo de Estados miembros ofrece orientación a otro sobre un problema concreto que le concierne, el asesoramiento entre homólogos, que reúne a homólogos experimentados de un pequeño número de administraciones nacionales para asesorar a un Estado miembro que quiere informarse sobre la elaboración o aplicación de una política para atender a un problema concreto que le afecta, el Monitor de la Educación y la Formación, que pasa revista anual a los avances de los Estados miembros hacia los objetivos y valores de referencia de ET 2020 y cuyos análisis contribuyen a la evaluación de los avances socioeconómicos en general por parte de los Estados miembros en el marco del Semestre Europeo, las herramientas y enfoques comunes de referencia creados en grupos de trabajo o en actividades de aprendizaje mutuo, las actividades de consulta y cooperación con las partes interesadas, incluida la sociedad civil, y con organizaciones empresariales y de interlocutores sociales tales como la Cumbre Europea sobre Educación y el Foro de Educación, Formación y Juventud

financiación de actividades de apoyo a políticas y proyectos innovadores a través del programa Erasmus+. Para un mayor abundamiento al respecto, se recomienda la visita a la web: https://ec.europa.eu/education/policies/european-policy-cooperation/et2020-framework_es, [último acceso a fecha de 17/07/2020].

${ }^{5} \mathrm{Al}$ respecto del seguimiento de la implantación del citado proceso son muy escasos los trabajos entre la doctrina española. En este sentido sí que se incluye el de la Profesora Magdalena Nogueira Guastavino "El constructivismo como base teórica del nuevo método docente y su proyección en los Estudios de Derecho del Trabajo", Revista de Derecho del Trabajo y de la Seguridad Social, núm. 27, 2011, p. 4. 
técnica del soft-law -dado que la UE no tiene competencias reconocidas en materia educativa-, una serie de orientaciones estratégicas que ha de ser seguida por los Estados miembros interesados en participar en el proceso de convergencia diseñado a partir del EEES y, por tanto, en acceder también a esta suculenta financiación. Pues bien, de entre estas orientaciones, es considerado un cambio esencial la eliminación de las barreras que rodean a las Universidades europeas, lo cual se alcanzaría, no sólo a partir de la apenas citada renovación de los planes de estudio sobre la base de facilitar las comparaciones y el desarrollo de prácticas a nivel europeo, sino especialmente fomentando la movilidad del profesorado y del estudiantado para que así se sustituya "la fuga" por la "circulación de cerebros" ". Y, lógicamente, materializar tal circulación e internacionalización exige, para los Estados miembros, el dominio de lenguas distintas a la propia. En este punto la Comunicación de la Comisión refiere expresamente como instrumento de base para agilizar la movilidad intra-europea el Marco Común Europeo de Referencia ${ }^{7}$ (MCER, en adelante) elaborado en el año 2001 -aunque sus antecedentes suelen ubicarse por la doctrina ${ }^{8}$ en $1971^{9}$.

Con estas incógnitas despejadas a nivel europeo, su implementación por parte de las universidades españolas se produjo con relativa rapidez. El 13 de diciembre de 2000, la Conferencia de Rectores de las Universidades Españolas (CRUE) aprueba un documento que recoge el proceso de adaptación de las universidades a la Declaración de Bolonia ${ }^{10}$, desde el que se configura un específico procedimiento de intervención. La primera fase consiste en la implantación del sistema ECTS, la adopción de un sistema de calificaciones que permitan una conversión fácil a través del sistema ECTS y la introducción del suplemento al título; mientras que, en la segunda etapa, considera necesario abordar otras iniciativas como la introducción de currículos basados en competencias o la valoración de los niveles de calidad mediante parámetros transnacionales que resultasen reconocibles en el ámbito europeo ${ }^{11}$. Sin embargo, la respuesta por parte del legislador español se presentó

\footnotetext{
${ }^{6}$ El entrecomillado es una reproducción fiel de la expresión empleada en el documento COM(2006) 208 final, disponible en la web: https://ec.europa.eu/transparency/regdoc/rep/1/2006/ES/1-2006-208-ES-F11.Pdf, [último acceso a fecha de 20/07/2020].

${ }^{7}$ El documento íntegro está disponible en la web: https://rm.coe.int/1680459f97, [último acceso a fecha de 20/07/2020].

${ }^{8}$ Concretamente nos referimos a los trabajos de Álvaro García Santa-Cecilia: "Bases comunes para una Europa plurilingüe. Marco común europeo de referencia para las lenguas" en VV.AA.: El español en el mundo. Anuario del Instituto Cervantes, Plaza-Janés y Círculo de Lectores, Barcelona, 2002, pp. 13-34. Y de Neus Figueras "El Marco común europeo de referencia para las lenguas: de la teoría a la práctica", Carabela 57, febrero 2005, pp. 5 a 23. Esta revista está disponible en la web: https://cvc.cervantes.es/ensenanza/biblioteca_ele/carabela/57.htm, [último acceso a fecha de 20/07/2020].

${ }^{9}$ En este año tuvo lugar el simposio sobre La Enseñanza de Lenguas Modernas en la Educación de los Adultos que se celebró a instancias del Comité de Educación Extraescolar y Desarrollo Cultural del Consejo para la Cooperación Cultural del Consejo de Europa, reunido en la ciudad helvética de Rüschlikon. Allí se dio cita un equipo de acreditados lingüistas y profesores de lengua — conocido como el Grupo de Expertospara proveer las bases del establecimiento de un marco de referencia europeo en el ámbito de la enseñanza de lenguas para adultos.

${ }^{10} \mathrm{El}$ documento está disponible a través del enlace: http://www.eees.es/pdf/crue.pdf, [último acceso a fecha de 20/07/2020].

${ }^{11}$ La CRUE define los objetivos del EEES señalando que se persiguen cinco objetivos básicos, a saber: -La adopción de un sistema fácilmente legible y comparable de titulaciones, mediante la implantación, entre otras cosas, de un Suplemento al Diploma.

-La adopción de un sistema basado, fundamentalmente, en dos ciclos principales: pregrado y grado. El título otorgado al terminar el primer ciclo habrá de tener un valor específico en el mercado de trabajo europeo. El segundo ciclo llevará a la obtención de un Máster y/o Doctorado como ocurre en muchos Estados europeos. - El establecimiento de un sistema de créditos, como el sistema ECTS.
} 
extemporáneamente y, hasta el verano de 2003, no reguló el suplemento europeo al título o la aplicación del sistema de créditos ECTS, mediante Real Decreto de 1044/2003, de 1 de agosto y Real Decreto 1125/2003, de 5 de septiembre ${ }^{12}$-respectivamente-. A partir de ese momento comienza en nuestro país la regulación de todo el proceso de adaptación y homologación de los títulos universitarios.

Entre los aspectos esenciales de la adaptación, resultan especialmente destacables la estructura en tres ciclos de los estudios universitarios (grado, máster y doctorado), la duración mínima del grado de tres años, la aplicación del sistema de créditos ECTS, el sistema de evaluación y objetivos de enseñanza más complejos y centrados en las competencias, la existencia del suplemento europeo al título, el aprendizaje continuo a lo largo de toda la vida, la necesidad de tener en cuenta las necesidades sociales y las demandas de los empleadores, así como la potenciación de la movilidad. Aspectos todos ellos promocionados en la Comunicación del año 2006 mentada anteriormente y que supuso una adhesión sistemática -a pesar de las reticencias señaladas- al nuevo sistema universitario que permitía al proceso de convergencia despegar finalmente.

Por otra parte, tal como hemos tratado de reflejar en el título de este primer epígrafe al emplear la expresión "competencia lingüística", el conocimiento de un idioma per se no es el objetivo del EEES, sino que su finalidad es dotar a los ciudadanos de capacidades linguiísticas distintas a las propias para así garantizar la movilidad intra-europea. De ahí se deriva que otra de las características más identificativas del EEES es la utilización de una nueva terminología lo suficientemente abstracta como para poder ser aplicada en cualquier área de conocimiento, en cualquier titulación y, lo que resulta más trascendente, en cualquier Estado miembro de manera que sea factible materializar la finalidad última de la Declaración de la Sorbona: el diálogo institucional entre sistemas educativos para favorecer la circulación de conocimientos y la empleabilidad.

Consecuencia de ello es el empleo del término "competencia" -también intercambiable por "destrezas", "habilidades" o "capacidades"- para indicar el objeto o la meta de la enseñanza y del aprendizaje, tratando de referir con esta nomenclatura -la de competenciauna realidad dinámica, flexible y abierta. Lo suficientemente maleable, al fin y al cabo, como para adaptarse a cualquier contexto social, cultural, educativo y profesional. Por tal ha entendido la doctrina científica "13 "la aptitud para enfrentar eficazmente una familia de situaciones análogas, movilizando a conciencia y de manera rápida, pertinente y creativa, múltiples recursos cognitivos: saberes, capacidades, micro-competencias, informaciones, valores, actitudes, esquemas de percepción, de evaluación y de razonamiento" ${ }^{14}$; siendo

\footnotetext{
- La promoción de la cooperación europea para asegurar un nivel de calidad para el desarrollo de criterios y metodologías comparables.

-La promoción de una necesaria dimensión europea en la educación superior con particular énfasis en el desarrollo curricular.

${ }^{12}$ Las citadas normas son objeto de publicación en el BOE núm. 218, de 11 de septiembre de 2003 y BOE núm. 22, de 18 de septiembre de 2003, respectivamente.

${ }^{13}$ Son muy numerosos y variados los estudios en torno a la idea de "competencia" y como botón de muestra referimos en esta nota el de Juan Bautista Martínez Rodríguez: "Evaluar las universidades como práctica social, política y ética: Crítica a la teoría de las competencias", Cuadernos para la Educación Superior, Año 2004, pp. 57-73; el colectivo de los Profesores Juana María Tierno García, Pilar Iranzo García y Rosario Barrios Arós: "El compromiso organizativo e institucional para diseñar y evaluar competencias en la universidad", Revista de Educación, n 361, 2013, pp. 223-251 y, el monográfico de María José García San Pedro: Evaluar la integración de las competencias en la universidad: hoja de ruta para evaluar la integración efectiva de las competencias en los programas formativos y orientarla hacia la mejora, Mensajero, Bilbao, 2013.

${ }^{14}$ El entrecomillado procede de Juana María Tierno García, Pilar Iranzo García y Rosario Barrios Arós: "El compromiso organizativo e institucional...", op. cit., pág. 226.
} 
causa de argumentos encontrados que postulan desde la necesaria y oportuna reforma cualitativa de la Universidad para aumentar su calidad, hasta el desasosiego por adoptar un sistema que hace temblar los cimientos de nuestra cultura universitaria ${ }^{15}$, empujándola hasta páramos mercantilistas y utilitaristas impropios del foco de formación e irradiación cultural que debe ser la Universidad.

Esta última deriva somos conscientes de que en parte se ha producido. No hay más que observar, v.gr. el peso que la investigación asume en los distintos procesos evaluadores a los que se somete la carrera profesional universitaria frente al denostado papel que se adjudica a la docencia o, cómo la labor del docente universitario casi podría describirse como "desnaturalizada" dadas las misiones principalmente conectadas con su desempeño diario centradas en el control de los niveles de asimilación de conocimientos por parte del alumnado -a través de la evaluación continua, la vigilancia en las pruebas de conocimiento para evitar el fraude, etc.- y en la gestión de documentación relacionada con los extremos anteriores. Sin embargo, que ello se deba exclusivamente a la introducción del elemento de la competencia como objeto del proceso enseñanza-aprendizaje no deja de plantearnos serias dudas a las que buscamos una orientación positiva, justamente, desde el mismo concepto.

Como apenas se ha dicho las competencias también pueden ser definidas como "capacidades" siendo este otro sentido un valor al alza desde que fuera presentado por Amartya Sen como novedosa formulación de la idea de derechos a conquistar y a satisfacer por la Justicia Social ${ }^{16}$ del siglo XXI. En concreto desde esta perspectiva filosófico-jurídica las capacidades se presentan como formulación dinámica de los intereses y necesidades humanos, los cuales atendiendo a cada etapa histórica tienen uno u otro contenido. De manera que la capacidad es la posibilidad de hacer o no, de participar o no en sociedad, en política, en economía o en cualesquiera otras esferas de la vida humana y no sólo el resultado concreto de esa actividad - v.gr. comprar, estudiar, ser un cargo político, etc.-. Esta abstracción del derecho definido no por su resultado, sino por la acción que en él se contiene, es el elemento que utiliza el EEES para dotar de contenido a la competencia. De esta forma la enseñanza se transforma en un proceso de aprender a aprender que puede debe- prolongarse a lo largo de toda la vida. La función del docente en la Universidad -de forma paralela a lo que sucede en los niveles educativos inferiores- se centra en utilizar sus conocimientos de manera holística y enfatizando el aprendizaje del alumnado como sujetos activos, de manera que así ha de diseñar su estrategia docente, abarcando desde los objetivos, la materia hasta la evaluación.

Este tipo aprendizaje basado en competencias -o en capacidades- permite, como se ha apuntado con anterioridad, que el principio de reconocimiento mutuo que rige en el escenario jurídico-político europeo no sólo sea factible, sino respetuoso con la idiosincrasia de cada sistema educativo nacional. De esta manera los Estados miembros no se mostrarán tan reticentes a reconocer planes de estudio, puesto que lo que se garantiza en cada uno de ellos son unas capacidades adquiridas que, a la postre, se dotarán del contenido que requiera

\footnotetext{
${ }^{15} \mathrm{Al}$ respecto de la correlación existente entre la educación por competencias y su conexión con la inserción laboral se realiza una interesante reflexión en el trabajo del Profesor Morales Ortega: "Relaciones Laborales en la empresa: negociación, resolución de conflictos y gestión de personal. Un acercamiento desde la simulación" en Carmen Sánchez Hernández (Coord.): Aprendizaje colaborativo y técnicas de simulación, Tirant lo Blanch, Valencia, 2020, pág. 143.

${ }^{16}$ Aunque su obra está dirigida al estudio de la economía del bienestar, la aproximación desde las capacidades como nueva necesidad a satisfacer por la Justicia Social aparece claramente presentada en su The Idea of Justice, Belknap Press, New York, 2011.
} 
cada contexto nacional en cualquiera de sus esferas -jurídica, social, educativa, económica, cultural-.

La formación universitaria, por tanto, se aleja de los contenidos y se centra en el proceso de aprendizaje, el cual ha sido estructurado en tres niveles de competencias: las del Grado, las del Título y las específicas de la materia. Se trata de una estructura gradual, de manera que la programación de las clases y seminarios debe buscar el ascenso desde las competencias más accesibles -o generales- hasta las más complejas. Ello ha conducido a unos estudios en las disciplinas jurídicas menos centrados en el aprendizaje de conceptos y más encaminados a la adquisición de competencias específicas que capaciten al estudiantado para asumir un rol activo, implicado con la docencia, capaz de responder a cuestiones, resolver problemas jurídicos o realizar análisis críticos del régimen jurídico de las distintas instituciones. De forma paralela el profesor de Derecho asume una función que abarca un número importante de actuaciones que exceden con creces de la de transmisor de conocimientos $-v \cdot g r$. tutorías, seguimientos y planificaciones son algunos de los términos que pueden expresar la labor diaria del profesor-.

En la teoría -o sobre el papel- el diseño del aprendizaje por competencias presenta un interesante enfoque metodológico que, sin embargo, en la práctica española no es demasiado exitoso ${ }^{17}$. En efecto, aunque la Declaración de Bolonia proponía ese Espacio Europeo de Enseñanza Superior como medio privilegiado para fomentar la movilidad y la empleabilidad de los ciudadanos, la opción española de aplicar a "coste cero" el nuevo sistema de créditos ECTS y los nuevos planes de estudio en base al tripe ciclo (Grado, Máster y Doctorado), unido a la reducción posterior del número de profesores como consecuencia de la crisis económica, que a su vez ha influido de forma muy negativa en la empleabilidad, ha producido efectos perniciosos en la enseñanza universitaria. No se han observado los límites recomendados para el número de alumnos por profesor -ratioespecialmente en los Grados de Ciencias Jurídicas y Sociales. Y, en cuanto a la movilidad, tampoco se puede hablar de un objetivo logrado, a lo que se añade que en España el proceso de Bolonia ha venido acompañado por una revolución pedagógica que, en muchos casos, no se ha aprovechado de la forma más adecuada en beneficio de la docencia en materias jurídicas, produciéndose un descenso generalizado del aprovechamiento por parte del alumno - por la proliferación de actividades poco útiles- y una complicación innecesaria del papel del profesorado que se ha visto obligado a asumir una mayor carga de trabajo por el elevado número de estudiantes por clase, que encuentra dificultades para coordinarse con los compañeros, que afronta dificultades logísticas importantes y, que percibe el Plan Bolonia como una herramienta que le resta autonomía ${ }^{18}$ por venir impuestas las competencias desde el nivel regional europeo, por entidades externas a la universitaria e, incluso, desde la propia Universidad.

Ejemplo de esta imposición en España son las competencias exigidas por la ANECA a cada Grado, las cuales se concretamente para el Grado en Derecho se refieren en su Libro Blanco $^{19}$, indicando como específicas conseguir la percepción de carácter unitario del ordenamiento jurídico y de la necesaria visión interdisciplinar de los problemas jurídicos; tomar conciencia de la importancia del derecho como sistema regulador de relaciones sociales; desarrollar capacidades para utilizar los principios y valores constitucionales

\footnotetext{
17 En este sentido se ha pronunciado magistralmente Juan Bautista Martínez Rodríguez: "Evaluar las universidades como práctica social, política y ética...", op. cit., pág. 69.

18 De nuevo citamos a Juana María Tierno García, Pilar Iranzo García y Rosario Barrios Arós: "El compromiso organizativo e institucional...”, op. cit., pp. 239-240.

19 El enlace web a todos los Libros Blanco sobre competencias en Grados es el siguiente: http://www.aneca.es/Documentos-y-publicaciones/Libros-Blancos, [último acceso a fecha de 21/07/2020].
} 
como herramienta de trabajo en la interpretación del ordenamiento jurídico, para el manejo de fuentes jurídicas -legales, jurisprudenciales y doctrinales- y, para potenciar la oratoria jurídica; adquirir una conciencia crítica en el análisis del ordenamiento jurídico y desarrollar la dialéctica jurídica teniendo presente los valores y principios éticos; fomentar el trabajo en equipo, así como las habilidades de negociación y conciliación.

\section{La adaptación de la titulación en Derecho al proceso de convergencia del EEES.}

En el contexto apenas apuntado, la adaptación de la titulación en Derecho al proceso de Bolonia se inició con importantes dudas que dinamitaban incluso la propia conveniencia de atender a las exigencias de ordenación temporal y contenido indicadas por el EEES.

Estos recelos, compartidos por una parte importante de los Estados miembros de la UE, provocaron que fueran muchos los detractores al propio proceso y al Plan Bolonia. Y es que parecía contradictorio que, si se había decidido garantizar un período de formación y un examen de capacitación para el acceso a las profesiones de Abogado y Procurador, se planteara reducir la carrera a 240 créditos, disminuyendo la duración de la titulación a cuatro años, cuando en la mayoría de las Facultades de Derecho, como sucedía en el caso de Málaga, alcanzaba un total de cinco años. Otro problema añadido era la propia especialidad de la materia de Derecho cuyo contenido está inextricablemente unido a la idiosincrasia de los pueblos, su cultura, su historia y las relaciones sociales subyacentes al ámbito jurídico. Ello provocó que mientras algunos países miembros, como lo era el Reino Unido, considerasen innecesaria -en general- la convergencia entre los sistemas educativos, otros hayan excluido expresamente los títulos de Derecho -Alemania y Polonia- ante el temor de erradicar por esta vía la esencia de sus propios ordenamientos jurídicos.

No estando claramente asentado o, al menos no se percibe así por los Estados miembros, que la propia esencia de la convergencia comunitaria lo que busca es, justamente, fomentar la diversidad nacional a partir del principio del reconocimiento mutuo ${ }^{20}$, los temores a perder otra esfera más de soberanía nacional tuvieron como consecuencia un abandono de calado entre los países considerados tractores de la UE; si bien otros -como es el caso español- se adhirieron sin mayores reticencias que las apuntadas.

En España, la Ley Orgánica 4/2007, de 12 de abril ${ }^{21}$, por la que se modificaba la Ley Orgánica 6/2001, de 21 de diciembre, de Universidades, establecía en su artículo 87 la obligación de las Universidades de adoptar las medidas necesarias para completar la plena integración del sistema español en el Espacio Europeo de Enseñanza Superior. La propia Ley estructuraba ya las enseñanzas universitarias en tres ciclos: Grado, Máster y Doctorado -artículo 37- y habilitaba al Gobierno para adoptar las directrices y condiciones para la obtención de los títulos universitarios de carácter oficial -artículo 35-.

\footnotetext{
${ }^{20}$ En este mismo sentido se ha pronunciado el Profesor José García Añón cuando apunta a que el objetivo del proceso de convergencia no es tanto realizar la equiparación con el resto de universidades europeas como propiciar la diversidad e idiosincrasia de cada una de ellas y, al mismo tiempo, favorecer y posibilitar la movilidad, flexibilizando las estructuras y eliminando, en la medida de lo posible, obstáculos burocráticos, "Los estudios de derecho en Europa y la reforma de los planes de estudio: reflexiones y propuestas" en José García Añón (Coord.): Los estudios de Derecho en Europa: Alemania, Francia, Italia, Reino Unido e Irlanda, Universidad de Valencia, 2008, pág. 20.

${ }^{21}$ Publicada en el BOE $n^{\circ} 89$, de 13 de abril.
} 
En virtud de dicha autorización, se aprobó el Real Decreto 1393/2007, de 29 de octubre, modificado posteriormente en $2010^{22}$ y $2015^{23}$, por el que se establece la ordenación de las enseñanzas universitarias oficiales. Este Real Decreto destaca por la desaparición del catálogo de titulaciones, lo que daba libertad a cada Universidad para confeccionar sus títulos y por la existencia de directrices propias generales para aquellos títulos que habilitasen para el acceso o ejercicio de actividades profesionales.

El nuevo Grado en Derecho tiene como finalidad "la obtención por parte del estudiante de una formación general, en una o varias disciplinas, orientada a la preparación para el ejercicio de actividades de carácter profesional" (art. 9 RD 1393/2007). Frente a los 300 créditos que componían la antigua Licenciatura, el Grado se integra por 240 créditos ECTS, entre los que se incluye el trabajo fin de grado, de entre 6 y 30 créditos, a presentar hacia el final de los estudios y reorientado a la evaluación de las competencias adquiridas durante la titulación. También las prácticas externas, que podían tener un máximo de 60 créditos. Cada crédito ECTS implica entre 25 y 30 horas de trabajo, distribuidas entre horas de trabajo presenciales (clases magistrales, seminario, clases prácticas, tutorías, etc.) y horas no presenciales (estudio personal, preparación de casos, lecturas propuestas, etc.). Hay que tener en cuenta que esta norma fue modificada por RD 43/2015, de 2 de febrero que introdujo la posibilidad de que los planes de estudio conducentes a la obtención del título de Grado poseyeran entre 180 y 240 créditos, abriendo así la vía a los Grados de tres años -conforme a su art. 12.2-. Los planes de estudios debían configurarse, además, por un mínimo de 60 créditos de formación básica, ofertada en su primera mitad -art. 12.5 RD 43/2015-. Estos créditos presentan la especialidad de poder ser objeto de reconocimiento automático en otros títulos conforme al art. 13 del mismo cuerpo normativo, pretendiéndose de esta forma que fuera un acicate no sólo para disuadir potenciales abandonos en el primer año de contacto con los estudios superiores universitarios, sino, también favorecer la movilidad nacional y, especialmente, la internacional de los estudiantes.

El Real Decreto 43/2015 fue objeto de numerosas críticas por parte de la comunidad universitaria, generándose una postergación de su aplicación hasta que el Consejo de Universidades adoptó, mediante Resolución de 11 de mayo de $2017^{24}$, la decisión final de adoptar un acuerdo en el que se ordenan las enseñanzas universitarias oficiales de Grado. En el Anexo II se recogen los títulos oficiales universitarios de Grado en los que los planes de estudio poseen una carga lectiva de 240 ECTS; entre los cuales figura el Grado en Derecho.

A la vista de estas disposiciones normativas, la Universidad de Málaga, por lo que respecta a la titulación del Grado en Derecho, obtuvo verificación positiva del Consejo de Universidades, previo informe favorable de la ANECA, así como autorización de la Junta de Andalucía. Una vez establecido el carácter oficial del Título, fue llevada a cabo su inscripción en el Registro de Universidades, Centros y Títulos por acuerdo del Consejo de Ministros de 1 de octubre de 2010 25 . El Plan de Estudios del Grado en Derecho se publicó en virtud de Resolución de 27 de febrero de 2013 de la Universidad de Málaga ${ }^{26}$, y allí se disponía, como cláusula de cierre y como tributaria de las más genéricas previsiones contenidas en el artículo 57.5 de la Ley Andaluza de Universidades, la exigencia a los estudiantes de acreditar el nivel B1 de conocimiento de idioma distinto del castellano o de

\footnotetext{
${ }^{22}$ Este fue el RD 861/2010, de 2 de julio, publicado en el BOE n $^{\circ} 161$, de 3 de julio.

${ }^{23}$ Se trata del RD 43/2015, de 2 de febrero, publicado en el BOE n ${ }^{\circ} 29$, de 3 de febrero.

${ }^{24}$ Publicado en el BOE $\mathrm{n}^{\circ} 114$, de 13 de mayo.

${ }^{25}$ Publicado en el BOE $n^{\circ} 273$, de 11 de noviembre.

${ }^{26}$ Publicado en el BOE $n^{\circ} 80$, de 3 de abril.
} 
las demás lenguas españolas cooficiales para la expedición del título con carácter previo a la expedición del correspondiente título universitario oficial de Graduado/a en Derecho y según lo estipulado en el Marco Europeo de Referencia para las Lenguas.

A partir de este momento normativo y temporal, somos testigos de la irrupción en nuestros planes de estudio de la docencia multilingüe; lo cual exige que en este ensayo encaremos dos procesos distintos que necesariamente convergen en la propuesta final. Uno de ellos abunda en presentar los ingredientes cuyo resultado fue aquella Resolución de la Universidad de Málaga del año 2013. El otro refiere el modo en que se implementó y las consecuencias derivadas para el estudiantado, el profesorado y el entero proceso de enseñanza-aprendizaje.

3.1. La docencia en lengua extranjera de asignaturas de contenido jurídico y su introducción en los planes de estudio de la Universidad de Málaga: especial atención al Grado en Derecho.

En lo que respecta específicamente a la docencia en lengua distinta al castellano -o a las cooficiales- su recorrido histórico anterior al EEES apenas había tenido visibilidad en nuestro país. A pesar de que desde la década de los años ochenta algunas universidades privadas españolas sí que ofrecían cursos que combinaban las estancias en el extranjero con la consiguiente inmersión lingüística ${ }^{27}$ puesto que fue en el año 1987 cuando se lanzó el Programa Erasmus para estudiantes de niveles superiores- las Universidades públicas, en general, poco tenían andado por este sendero. A partir del año 2000, tal vez auspiciados por las distintas actuaciones desarrolladas desde el Comité de Educación Extraescolar y Desarrollo Cultural del Consejo para la Cooperación Cultural del Consejo de Europa -o quizás motu proprio- algunos profesores universitarios comienzan a impartir clase en idioma distinto al castellano para fomentar la movilidad que se lanza de forma exponencial a partir del año 2013 con la implementación del nuevo formato Erasmus+ -cuyo más reciente programa ${ }^{28}$ tiene un emplazamiento de seis años, es decir, desde 2021 y hasta 2027-.

Al margen de estas iniciativas aisladas no pueden hallarse referencias normativas a nivel nacional que otorguen amparo jurídico a la introducción de la docencia en lengua extranjera en el ámbito universitario español. Distinto es lo que sucede a nivel autonómico $^{29}$. Una vez más las Comunidades Autónomas han utilizado el vacío normativo -casi dejadez, podríamos pensar- del legislador nacional para regular una materia que se revela esencial para alcanzar unas más elevadas cuotas de movilidad interregional e internacional y, por consiguiente, un mayor nivel de empleabilidad entre la ciudadanía.

\footnotetext{
27 En este sentido se pronuncia María Ángeles Martín del Pozo en su "Formación del profesorado universitario para la docencia", Revista de Docencia Universitaria, vol. 11 (3), Octubre - Diciembre 2013, pág. 203.

${ }^{28}$ Nos referimos a la Propuesta 2018/0191 (COD) de Reglamento de ordenación del Programa Erasmus, (EU)

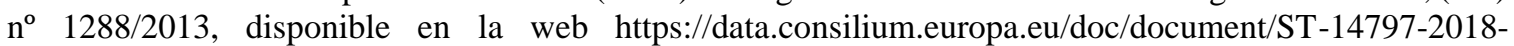
INIT/en/pdf, último acceso a fecha de 20/07/2020.

${ }^{29}$ Un interesante estudio estadístico al respecto de las actuaciones nacional y autonómica en lo que se refiere a la acreditación del nivel de lengua inglesa en las Universidades españolas fue publicado por Ana Halbach, Alberto Lázaro Lafuente y Javier Pérez Guerra bajo el título "La Acreditación del Nivel de Lengua Inglesa en las Universidades Españolas", Bristish Council, marzo, 2010, disponible a través de la web https://www.britishcouncil.es/sites/default/files/british-council-la-acreditacion-del-nivel-de-lengua-inglesa2010.pdf, último acceso a fecha de 20/07/2020.
} 
Para el caso andaluz, aunque la promoción del plurilingüismo halló amparo normativo en el artículo 57.5 de la Ley Andaluza de Universidades ${ }^{30}$-aprobada precisamente en enero del año 2013-, incluso con anterioridad a su positivización pueden rastrearse importantes reminiscencias en el Modelo de Financiación de las Universidades Públicas de Andalucía. Este programa fue publicado a partir del Acuerdo de 10 de julio de 2007 del Consejo de Gobierno $^{31}$ y a pesar de que se previó inicialmente para los años 2007 a 2011 posteriormente ha sido prorrogado ${ }^{32}$ hasta el curso académico 2019/2020 en que se ha publicitado la propuesta del nuevo modelo ${ }^{33}$ para el período 2017/2021. Independientemente de la estructura y las motivaciones político-económicas que justifican la existencia de uno u otro modelo, interesa a efectos de este estudio destacar el tratamiento que en el instrumento se ha realizado -y va a realizarse- del bilingüismo en la docencia universitaria. Tal extremo puede caracterizarse como de continuidad puesto que, si la internacionalización y la movilidad de investigadores y estudiantado era un objetivo estratégico en el anterior modelo, en el futuro se elevan las cotas conectadas con estas metas. Ello justifica que, en el nuevo modelo financiador, la docencia en lengua extranjera se inserte entre los resultados en formación ${ }^{34}$, investigación ${ }^{35}$, transferencia $^{36}$ y docencia ${ }^{37}$, un abanico de ámbitos objetivos mucho mayor que aboga por la transversalidad, frente al más incipiente previsto en modelo anterior. Línea de continuidad, decimos, que se refleja en los objetivos estratégicos configuradores de los "Contratos Programa" -los instrumentos políticos que permiten acordar las metas a alcanzar por las Universidades andaluzas signatarias y de cuya evaluación depende la distribución y asignación presupuestaria, de conformidad con los artículos, 57.6, 87.4 y 87.7 de la Ley Andaluza de Universidades- que cada anualidad deben ser aceptados por los Centros de cada Universidad y, sucesivamente, por los Departamentos o Áreas de conocimiento a ellos adscritos.

Además de reportar un incremento en las cuantías presupuestarias destinadas a los Centros o Facultades y a los Departamentos o Áreas de Conocimiento si alcanzadas las metas indicadas 38 , la suscripción del contenido de estos "Contratos Programa", como afirmamos, ha sido el motor impulsor de la docencia en lengua extranjera en el nivel docente universitario puesto que, ante la ausencia de un imperativo en la redacción del precepto antes citado -el artículo 57.5 LAU-, la dotación económica se ha convertido en una valiosísima y eficiente herramienta propulsora y ello en la medida en que tal objetivo -el del bilingüismo-, una vez incluido en "Contrato Programa", si es aceptado como reto a satisfacer a nivel de Centro y de Departamento, reporta un interesante incremento en sus respectivos presupuestos anuales.

Por consiguiente, recibido el artículo 57.2 LAU en la cláusula de cierre inserta en la Resolución de 27 de febrero del 2013 la Universidad de Málaga confluyen en este contexto universitario dos elementos esenciales para dotar de contenido la meta de la convergencia

\footnotetext{
${ }^{30}$ Aprobada por Decreto Legislativo 1/2013, de 8 de enero y publicada en BOJA $\mathrm{n}^{\circ} 8$, de 11 de enero.

${ }^{31}$ Publicado en el BOJA no 146 de 25 de julio de 2007.

${ }^{32}$ Las prórrogas han tenido ocasión a partir de los Acuerdos del Consejo de Gobierno celebrados en torno a finales del mes de diciembre de cada año desde el 2011 y hasta el 2016.

33 El texto de la nueva propuesta está disponible en la web https://delegacionfceye.files.wordpress.com/2017/03/modelo-financiacic3b3n-diciembre.pdf, último acceso a fecha de 21/07/2020.

${ }^{34}$ Así se indica en la página 16 del borrador del nuevo Modelo de Financiación.

35 Ídem, páginas 6, 7, 13, 14 y 15.

36 Ídem, página 7.

37 Ídem, páginas 13, 14 y 15.

${ }^{38}$ El cual suele rondar entre el $10 \%$ y el $15 \%$ de presupuesto adicional, tal y como se indica en el apartado 12 de la actual propuesta del Modelo de Financiación y en el artículo octavo del anterior Modelo.
} 
idiomática propuesta desde el EEES: exigir al alumnado el conocimiento de idiomas -sin cuya acreditación el título en educación superior universitaria no será expedido- y fomentar en y desde la Universidad la formación bilingüe. Dos itinerarios estos a cuyo deslinde se dedican las líneas que siguen.

3.2. La transversalidad del bilingüismo: la acreditación del conocimiento de idioma distinto al castellano y la oferta educativa universitaria en segunda lengua.

Estos dos circuitos, aunque distintos, están orientados a la misma finalidad que claramente se impulsaba desde Europa allá por la década de los años setenta del siglo pasado. Cuando en 1971 se iniciaron los simposios entre los grupos de expertos que buscaban configurar un marco europeo de referencia de lenguas estas variables, objeto de discusión y reflexión en España treinta años más tarde, ya habían sido identificadas como herramientas clave para fortalecer el Mercado Único Europeo, mejorar la empleabilidad del ciudadano y la cohesión comunitaria. Sin embargo, aun atendiendo a la misma finalidad, son dos mecanismos paralelos que puntualmente han sido tangentes. Por ello, porque han estado interconectados, hemos considerado necesario referirlos de forma conjunta a pesar de que sólo uno sostiene el Proyecto Docente que presentamos.

Tal y como se ha apuntado con anterioridad, de conformidad con la Declaración de Bolonia y la Comunicación $\mathrm{n}^{\circ} 187$ de la Comisión al Consejo del año 2006, la desaparición de las barreras entre las Universidades europeas es una de las finalidades clave del EEES. Para ello fomentar la movilidad entre el profesorado y el estudiantado se revela fundamental, lo cual definitivamente se imposibilita si no se poseen conocimientos idiomáticos que, a su vez, son incluidos como objetivo a alcanzar por aquellos países que deseen participar de la generosa financiación destinada a la implementación del EEES. El efecto dominó que describimos alcanza de lleno a la Universidad de Málaga, junto a las demás andaluzas, lo cual se refleja tanto en la redacción del artículo $57^{39}$ LAU, en la aprobación del Plan de Estudios de los Grados -entre los que se incluye el de Derecho que nos afecta-, en los modelos de financiación mentados en el epígrafe anterior que datan del año 2007 y, finalmente, en la ratificación del "Convenio Marco de Colaboración para la Certificación de Lenguas Extranjeras en las Universidades Andaluzas" ${ }^{40}$ firmado en julio de 2011.

Este "Convenio Marco" adquiere relevancia en este Proyecto en la medida en que ordena sólo a medias la solución a la exigencia contenida en el Plan de Estudios de los Grados relativa a acreditar el nivel de conocimiento de idiomas, debiendo las Universidades buscar otra solución complementaria a aquella para los casos que podrían llamarse de derecho transitorio. Solución complementaria que pasa, precisamente, por la oferta académica bilingüe. Para mayor claridad, procedemos a deslindar los supuestos.

Efectivamente el "Convenio Marco" nace de la voluntad concordataria de las Universidades andaluzas -centrada en articular mecanismos que solventen la existencia de un Modelo de Financiación que señala, como una de sus metas, el conocimiento de idiomas por parte del estudiantado universitario- y de la configuración de unos Planes de Estudio que, por aproximarse al EEES, habían incluido como conditio sine qua non tales destrezas

\footnotetext{
${ }^{39}$ Este artículo se dedica a ordenar la estructuración de las enseñanzas universitarias en grado, máster y doctorado y, además de referir que las Universidades fomentarán los intercambios de estudiantes y profesores a otros centros de estudio, en su apartado quinto subraya el deber de las Universidades de fomentar el plurilingüismo para, finalmente destacar que la financiación se vincula a los resultados en los cuales habrá de demostrarse el cumplimiento de estos objetivos.

40 Respecto del Convenio Marco, instrucciones precisas de su contenido se hallan en la web: http://deva.aac.es/?id=acreditaciondominiolenguas, [último acceso a fecha de 20/07/2020].
} 
idiomáticas. Ante este contexto el Convenio configura dos tipos de instrumentos orientados a la evaluación del conocimiento de lengua extranjera, pero referidos cada uno de ellos a una parcela de este proceso. Uno, que podríamos llamar externo, afecta a las actuaciones desarrolladas por el partenariado de Universidades andaluzas como grupo, siendo su objetivo forjar el acompasamiento de la actuación consensuada y coordinada ${ }^{41}$ de estas Universidades frente a la DEVA. Este que se había puesto en marcha a partir del Convenio firmado el día 2 de julio de 2011 adquiría rango institucional mediante la aprobación de la Resolución de 18 de marzo de 2013 de la Dirección Gerencia de la Agencia Andaluza del Conocimiento y, especialmente a partir de la aprobación del RD 1041/2017, de 22 de diciembre $^{42}$. Y en él se contenían los pasos a seguir por las distintas Universidades para obtener de la DEVA el certificado de calidad que validaba sus competencias en la evaluación de conocimientos en lengua extranjera por parte del estudiantado. El otro instrumento, el que podría identificarse como interno, alude al efectivo procedimiento de evaluación del conocimiento de la lengua extranjera desarrollado por cada Universidad respecto de sus alumnos. Esta otra herramienta -incluida, como decimos en el Convenio de julio de 2011- consistía en la incorporación -a través del Anexo II al mismo- de una serie de tablas de certificados aceptados por las Universidades andaluzas para la acreditación de lenguas extranjeras. Con este listado se esperaba dotar de homogeneidad a un proceso que ab initio había nacido deslavazado. De hecho, así ha sido, puesto que el citado elenco de entidades ha sido confirmado por la "Adenda Modificativa del Convenio de Colaboración" 43 suscrita en 2016 por las Universidades interpeladas en julio del año 2011. Al margen de esta "Adenda" todavía en vigor ${ }^{44}$ y que introduce algunas especificidades no comentadas $^{45}$ en el texto principal por no guardar relación directa con el objeto de este

\footnotetext{
${ }^{41}$ Efectivamente se cuenta con una completa estrategia autonómica en la que se incluye un "Procedimiento de acreditación de dominio de lenguas extranjeras en las Universidades Andaluzas", la configuración de una "Comisión de acreditación de dominio de las lenguas extranjeras", ambas en el seno de la Agencia Andaluza del Conocimiento, adscrita a la Consejería de Economía, Conocimiento, Empresas y Universidad fue creada por la Ley 16/2007, de 3 de diciembre, Andaluza de la Ciencia y el Conocimiento al configurar el Sistema Andaluz del Conocimiento, publicada en el BOE n 20 , de 23 de enero de 2008 y en el BOJA n ${ }^{\circ} 250$, de 21 de diciembre.

42 A través suya se fijan las exigencias mínimas del nivel básico a efectos de certificación, se establece el currículo básico de los niveles Intermedio B1, Intermedio B2, Avanzado C1, y Avanzado C2, de las Enseñanzas de idiomas de régimen especial reguladas por la Ley Orgánica 2/2006, de 3 de mayo, de Educación y, se establecen las equivalencias entre las Enseñanzas de idiomas de régimen especial reguladas en diversos planes de estudios y las de este Real Decreto. Se ha publicado en el BOE n $^{\circ} 311$, de 23 de diciembre.

43 El texto completo de la "Adenda" puede consultarse en la web: http://deva.aac.es/?id=acreditaciondominiolenguas, [último acceso a fecha de 21/07/2020].

44 Estas mismas condiciones se contienen específicamente en el documento: https://www.uma.es/SECRETARIAGENERAL/secgenfiles/AcreditacionB1/RelacionAcreditacionesRecon ocidas.pdf, [último acceso a fecha de 20/07/2020].

${ }^{45}$ En concreto la Adenda establece supuestos de exención de la acreditación del conocimiento de lengua extranjera. Siendo estos los siguientes:

1) Para la obtención del título de grado: Se eximirá del requisito de acreditar el nivel B1 de competencia en una lengua extranjera a quienes habiendo realizado estudios de Filología en una lengua moderna extranjera (sólo aplicable a lengua principal o maior), así como en Traducción (sólo aplicable a la lengua B), hayan concluido las enseñanzas que dan derecho a ello.

2) Se eximirá de acreditar hasta un nivel $\mathrm{Cl}$ de competencia lingüística a personas con una licenciatura de Filología en una lengua moderna extranjera, así como en Traducción (solo aplicable a la lengua B). En el caso de los Grados, se eximirá hasta el nivel establecido en los planes de estudios correspondientes.

3) Se eximirá de acreditar el dominio equivalente al nivel B2 de una lengua extranjera a quienes estén en posesión de un certificado de estudios de Bachillerato, o titulación afín conforme a sistemas educativos extranjeros (incluido el Bachillerato Internacional), impartidos en dicha lengua extranjera. Ello incluye: 1) hablantes nativos de una extranjera lengua que estén en posesión de un certificado de estudios de Bachillerato o titulación afín en su país; 2) estudiantes extranjeros que hayan realizado dichos estudios en sistemas
} 
Proyecto, interesa subrayar ahora que existía otro problema añadido para el que en absoluto tenía respuesta el "Convenio Marco" y para el que la oferta de docencia bilingüe sobre el que se asienta este Proyecto Docente resultó ser la solución.

La problemática que referimos alude a la satisfacción del cumplimiento del requisito de la acreditación del conocimiento en idiomas durante los primeros años de la implementación de los nuevos planes de estudio -que comenzó en el curso académico 2010/2011 en la Universidad de Málaga- y hasta que se aprobó oficialmente el procedimiento de validación a partir de la citada Resolución de 18 de marzo de 2013. Esto nos genera un intervalo de dos e incluso tres cursos académicos en que algunas promociones de estudiantes se encontraban finalizando los antiguos planes, pero que, finalmente, serían engullidos por la vorágine de los nuevos. Su situación era, cuando menos compleja, porque como suele referirse coloquialmente "a mitad de partido les habían cambiado las reglas de juego". Para ellos, desde la UMA, el Consejo de Gobierno en su sesión celebrada el 21 de julio de $2011^{46}$ aprobó una serie de normas en relación con la acreditación del conocimiento de idiomas antes de la expedición del título académico correspondiente, entre las cuales ${ }^{47}$ se citaba -en el apartado segundo, letra b)- el "haber obtenido como mínimo 12 ECTS correspondientes a asignaturas impartidas en una segunda lengua".

He aquí, pues, el punto de tangencia de ambos procedimientos del fomento del bilingüismo en la formación académica universitaria: el requisito relativo a poseer cierto nivel de conocimientos en lengua extranjera podía verse satisfecho en la UMA cursando asignaturas cuya docencia fuera impartida en una segunda lengua.

Independientemente de que este fuera un coadyuvante que realmente incrementara la oferta académica en lengua extranjera o si los Modelos de Financiación han sido los verdaderos propulsores de la incorporación de la docencia bilingüe en los nuevos Planes de Estudio de las Universidades españolas y concretamente en las andaluzas, sí que consideramos relevante el replanteamiento que, en general, ha sufrido la docencia universitaria y el papel que en la sociedad juega la Universidad. Un rol este centrado en la formación de personas y profesionales destinados a interactuar en un mundo y un mercado globalizados obliga a que la Universidad se responsabilice en la implementación de la

educativos y una lengua distintos a los de su país de origen; 3) estudiantes españoles que dispongan de un diploma de estudios equivalente al título de Bachiller realizado en lengua extranjera; 4) estudiantes extranjeros que hayan realizado el Bachillerato español. En ningún caso la exención significa que se puedan emitir a petición de los interesados certificados acreditativos de competencia lingüística de los niveles mencionados. De igual forma, se establece un plazo transitorio de dos años, durante el cual las universidades andaluzas firmantes del Acuerdo se comprometen a reconocer mutuamente los certificados de dominio de lenguas expedidos por cada una de ellas en aplicación del Acuerdo de 2016 y recogidos en la tabla de certificados reconocidos actualizada y vigente en cada momento, aun sin que hayan obtenido la acreditación de la Agencia Andaluza del Conocimiento.

${ }^{46}$ El documento está disponible en la web:

https://www.uma.es/secretariageneral/normativa/propia/consejo/Julio_2011/Anexo12.pdf, [último acceso a fecha de 21/07/2020].

${ }^{47}$ El resto de supuestos hace alusión a acreditar el conocimiento correspondiente al nivel B1 del marco común europeo de referencia para las lenguas; a elaborar y defender el trabajo o proyecto de fin de grado en una segunda lengua, a realizar una estancia en una universidad extranjera en el marco de un convenio de movilidad y haber obtenido un mínimo de 12 créditos ECTS y, a acreditar actividades académicas transversales realizadas en una segunda lengua y organizadas por los centros y/o departamentos dentro de la programación académica del curso, que en conjunto sean equivalentes a 12 créditos ECTS (workshops, conferencias, talleres, cursos intensivos, etc.). En cualquier caso, se dejaba claro que la competencia genérica alcanzada en el conocimiento de una segunda lengua, de acuerdo con lo dispuesto en los apartados b), c), d) y e) no implicará, en ningún caso, el derecho a obtener la certificación acreditativa correspondiente a nivel B1 del Marco Europeo de Referencia para las Lenguas. 
enseñanza y el aprendizaje multilingüe como competencia. Ello habrá de permitir que la Universidad se convierta en un nódulo más de la red de Universidades europeas que favorecen y facilitan la "circulación de conocimiento", materializado -tal papel de nóduloen recibir y atender a un flujo mayor de profesores y estudiantes internacionales -a través de los Programas Erasmus+ y Erasmus Mundus-, pero también incrementar el bagaje y la empleabilidad de los propios egresados. Con esta finalidad, los Estatutos de la Universidad de Málaga aprobados por Decreto 464/2019, de 14 de mayo ${ }^{48}$ contemplan como derecho de su estudiantado el "acceder a la formación en el conocimiento de idiomas para potenciar la internacionalización de la Universidad” -artículo 112.1.o)-. Así, aunque la oferta de asignaturas en lengua extranjera era un deber ya reconocido en el artículo 57.5 LAU, ha sido a partir de la nueva versión de los Estatutos de la universidad malagueña cuando ha alcanzado visibilidad como herramienta transversal en los estudios universitarios.

Para, efectivamente, materializar esta redescubierta función, la Universidad de Málaga ha articulado su propio cauce de actuación cuya ordenación normativa arranca del artículo 27.10 de la Constitución Española que reconoce la autonomía de las Universidades, recibido a partir del principio de autonomía organizativa universitaria contenido en el artículo 53.1.c) del Estatuto de Autonomía para Andalucía que contempla como competencia autonómica exclusiva la relativa a "la aprobación de los estatutos de las universidades públicas $\mathrm{y}$ de las normas de organización $\mathrm{y}$ funcionamiento de las universidades privadas"; y materializado a partir de la Ley Orgánica 6/2001 de Universidades, de la Ley Andaluza de Universidades y del Decreto 464/2019 por el que se aprueban los Estatutos de la Universidad de Málaga.

En el artículo 127.2 del Decreto 464/2019 expresamente se indica que "la Universidad de Málaga promoverá su internacionalización y su plena integración y homologación en el espacio europeo de educación superior" para lo que la calidad en la docencia se erige en principio general que habrá de asentarse, entre otros aspectos, en la formación integral del alumnado -ex artículo 132 Decreto 464/2019- garantizada por la revisión que, al respecto, se realiza para cada curso académico a través del Plan de Ordenación Docente General de la UMA, los planes de ordenación docente de cada Facultad y Escuela y los programas docentes de cada Departamento -artículo 135 del mismo cuerpo normativo-. La flexibilidad, pues, de estos instrumentos es la clave para que, en cada curso académico, sea el profesorado universitario quien asuma la responsabilidad y goce de la libertad de ofertar la docencia que tenga asignada en una lengua extranjera. A estos efectos los Centros o Facultades de la UMA en el período preparatorio para el diseño en cada curso académico de sus respectivos planes de ordenación docente remite a los Departamentos adscritos modelo de solicitud de impartición de docencia en lengua extranjera, al que, junto a la conformidad de la Dirección, habrán de incluirse la identificación de la asignatura cuya docencia se realizará de este modo, la del docente que la asume, un plan de contingencia para el caso de que no pudiera finalmente desempeñar la propuesta, la certificación de nivel de idiomas del profesorado implicado y la versión de la Guía Docente en el idioma distinto al castellano en que se impartiera la asignatura. Elevada la oferta al equipo Decanal y tras su aprobación por Junta de Facultad, se remite al Vicerrectorado de Estudios que ha de refrendar todo el procedimiento con su autorización -apartados 2.E. y 2.M. del Plan de Ordenación Docente de la Universidad de Málaga para el curso académico 2020-2021 ${ }^{49}$.

\footnotetext{
${ }^{48}$ Publicados en BOJA no 93, de 17 de mayo de 2019.

49 Este documento está disponible en la web: https://www.uma.es/servicio-ordenacionacademica/cms/menu/plan-de-ordenacion-docente/, [último acceso a fecha de 21/07/2020].
} 


\section{Propuesta para la asignatura Derecho del Trabajo y la Seguridad Social del} Grado en Derecho. Su diseño a partir de dos postulados educativos.

A efectos de encuadrar adecuadamente la asignatura sobre la que pivota este estudio a efectos de clarificar posibles dudas sobre su incardinación en el plan de estudios, el peso que tiene en referencia a otras asignaturas o el nivel de conocimientos jurídicos de los alumnos a los que se dirige esta propuesta -de manera que sea comprensible su grado de participación o las respuestas ante las dificultades que plantea impartir docencia en lengua distinta al castellano-, consideramos necesario dar noticia de su concreta ubicación espaciotemporal.

El Plan de Estudios del Grado en Derecho se publicó, como apenas se ha referido, en virtud de Resolución de 27 de febrero de 2013 de la Universidad de Málaga y en su estructura pueden diferenciarse materias de formación básica y formación obligatoria, optativas, prácticas externas y trabajo fin de grado. El número de créditos asignado a cada uno de estos bloques se corresponde con un total de 64 ECTS correspondientes a la formación básica, mientras que para la formación obligatoria se dedican 116 ECTS -entre los cuales sólo 6 ECTS están previstos para cursarse en la realización de prácticas externasLos créditos de optatividad se cuantifican en 54 ECTS y para el Trabajo Fin de Grado se conservan los 6 ECTS restantes.

La asignatura que nos ocupa, por su parte, se incardina entre la denominada formación obligatoria lo que explica que se imparta durante el segundo semestre del penúltimo curso del Grado con un valor total de 9 ECTS equivalentes a 63,75 horas de trabajo para el estudiantado y a 81 horas de dedicación para el profesorado.

Así presentada la asignatura, restaría dar cuenta de por qué se alude en la rúbrica de este tercer epígrafe a dos pilares o postulados sobre los que edificar nuestra propuesta, los cuales, además y tal como habrá podido observarse por los títulos de los apartados que componen esta parte postrera, responden a una concreta y personal forma de entender la docencia universitaria, desde la que pretendemos contribuir -sin desconocer nuestra pequeñez- a reflexionar sobre el papel de la Universidad pública tanto en la enseñanza como en la entera sociedad. A esta justificación, pues, se destinan las líneas que siguen.

\subsection{Apostar de forma equilibrada por el valor de uso y por el valor de cambio del conocimiento.}

En el estudio del ámbito jurídico laboral es habitual encontrar y hacer referencias a la "teoría del valor" de Marx; sin embargo, lo que no suele ser tan frecuente es hallarla aplicada a la esfera de la enseñanza, aún menos a nivel universitario. Cualquier alusión a ella puede considerarse un tropiezo, más que un hallazgo, porque uno nunca se lo espera y porque, casi siempre, suele tener un carácter abrupto el encuentro.

Esto, justamente, es lo que ha sucedido cuando hemos tratado de aproximarnos a los ensayos existentes en torno al papel de la Universidad en la sociedad y en la enseñanza. Parece de rabiosa actualidad -tal vez inducido ello por la mutación generalizada a no presencial de la docencia universitaria a raíz de la pandemia SARS-COVID-19- reflexionar acerca de cómo ha virado -o lo está haciendo- la función de la institución universitaria. Reflejo de ello son desde artículos periodísticos de opinión que excorian -aunque no faltos de razón a nuestro juicio-, como el intitulado The decline of universities, where students 
are customers and academics itinerant workers ${ }^{50}$ hasta libros monográficos de mayor rigor reflexivo, como sucede con la Crítica de la razón precaria. La vida intelectual ante la obligación de lo extraordinario ${ }^{51}$, pasando por inquietantes artículos científicos marcadamente ideologizados como la "Aproximación marxista a la relación conocimientovalor en la economía capitalista contemporánea" ${ }^{52}$. Pues bien, la conclusión que podría extraerse de este plantel de ejemplos, plurales tanto por las aproximaciones como por los tipos de trabajo que los sustentan, es que efectivamente la Universidad pública especialmente sus integrantes- se debate entre caer en brazos del valor de cambio del conocimiento -un terreno este que parece ser ya la ubicación definitiva de la privada- $o$ mantenerse firme para lograr afianzar el valor de su uso.

La cuestión es que mientras el valor de cambio aludiría al precio por el que es canjeable profesionalmente el conocimiento, el valor de uso abunda en el enriquecimiento personal de quien lo posee, lo cual podría llevarnos a inferir que, en efecto, son caras de la misma realidad. De forma directa o indirecta nuestros conocimientos y habilidades, aunque hayan sido adquiridos no para "ponerlos en venta" sino para nuestro disfrute personal, finalmente terminan incidiendo en aquellos que mercantilizamos dado que, indisolublemente, convergen en la misma persona que, al fin y al cabo, es el sujeto de la relación laboral y profesional. Por ende, imaginar un conocimiento destinado a usos exclusivamente lúdicos y otro únicamente productivo es tan irreal como pensar en el ser humano apolítico o en que se pueden poseer criterios objetivos puros.

Sin embargo y, en contraste con esta extrema afirmación anterior, sí es cierto que se producen descompensaciones, aumentando el peso de un platillo de la balanza en detrimento del otro, aunque este no desaparezca nunca por completo. Por lo general en la actualidad, el platillo preferido parece ser el del valor de cambio del conocimiento, mientras que el del valor de uso resulta minusvalorado por la Universidad -entiéndase, por sus planes de estudio, por sus autoridades, por los procesos de promoción, etc.- al no conectar de forma perfecta con los objetivos de la productividad y la competitividad global. De hecho, esta disonancia justifica que en el ranking mundial más prestigioso de Universidades -públicas y privadas- los criterios de selección estén relacionados, entre otros, con la transferencia del conocimiento al mundo empresarial ${ }^{53}$. La dificultad, pues, no está en identificar cuál es el platillo preferido, sino cómo contribuir a reequilibrar ambos $\mathrm{y}$, en todo caso, si esta nivelación resulta necesaria para la pervivencia de la propia institución universitaria.

\footnotetext{
${ }^{50}$ No se cita este artículo como instrumento de investigación, sino exclusivamente para mostrar de forma fehaciente que, de facto, existe una generalizada preocupación por los derroteros que asume la Universidad. Aunque el artículo de opinión fue publicado el día 30 de mayo de 2020, puede consultarse el mismo en la web: http://www.smh.com.au/national/the-decline-of-universities-where-students-are-customers-andacademics-itinerant-workers-20200528-p54xbd.html, [último acceso a fecha de 21/07/2020]. Su autora es Elisabeth Farrelly y el periódico en que se publica The Sydney Morning Herald.

${ }^{51}$ La cita completa de este ensayo es López Alós, Javier: Crítica de la razón precaria. La vida intelectual ante la obligación de lo extraordinario, Libros de La Catarata, Madrid, 2019.

52 Sus autores son Silvia Odriozola Guitart y Henry Colina Hernández, está disponible en la web: https://www.redalyc.org/pdf/3215/321549303004.pdf, [último acceso a fecha de 20/07/2020]. La investigación, aunque no tan actual como las dos referencias anteriores se publicó en la revista Textos \& Contextos (Porto Alegre), v. 15, no 2, ago./dic. 2016, pp. 264-274. Si incluimos ambas referencias -la virtual y la física- es porque, de hecho, nosotros sólo hemos tenido acceso a la primera, aunque allí se refiere dónde se publicó en papel.

${ }^{53}$ Estos criterios y los datos relativos a la ordenación de Universidades en función de ellos pueden consultarse en la web: https://www.timeshighereducation.com/world-university-rankings/2020/worldranking\#!/page/0/length/25/sort_by/rank/sort_order/asc/cols/stats, [último acceso a fecha de 21/07/2020].
} 
En este sentido de su supervivencia, consideramos adecuado rescatar unas líneas que a comienzos del siglo pasado escribía Ortega y Gasset sobre la misión de la Universidad ${ }^{54}$ donde, se decía, "se cultiva la ciencia misma, se investiga y se enseña a ello", haciendo así referencia a las funciones sobre las que se erigían los modelos de la Universidad Imperial napoleónica ${ }^{55}$ y de la Universidad humboldtiana ${ }^{56}$. Cierto es que, probablemente, lo hayamos leído en infinitud de ocasiones, empero nunca o, casi nunca, se completa la frase con su otra mitad, aunque a nuestro criterio esta sea, justamente, la más trascendente, por ensalzar el verdadero valor de la Universidad en la sociedad. Nos referimos a aquella reflexión que, tras criticar el que la enseñanza superior no sea más que profesionalismo e investigación -esto es: valor de cambio del conocimiento-, rescata de la época en que la Universidad fue creada -en torno al siglo XI en la Edad Media- cómo el centro del conocimiento lo ocupaba la cultura. Eso que hoy se presenta como "cultura general", se le acusa de ser un apéndice inútil y se rechaza por improductivo. Esa cultura, ese universum -reunido en un todo- procedía de la historia, la filosofía, la teología y las artes y permitía permiten todavía hoy- que el ser humano encuentre las ideas claras sobre el Universo que habita, que construya sus convicciones sobre las cosas y sobre el mundo. Cultura, por tanto, es "el sistema vital de las ideas de cada tiempo. No es ciencia. Por eso es ineludible crear de nuevo en la Universidad la enseñanza de la cultura o de sistemas de las ideas vivas que el tiempo posee. Esa es la tarea universitaria radical. Eso tiene que ser, antes y más que ninguna otra cosa, la Universidad".

Sin embargo y, a pesar de que para un intelectual de tan elevada talla y mundialmente reconocido, esta fuera la piedra axial de la misión universitaria en la sociedad, los más recientes estudios ${ }^{57}$ al respecto muestran que, incomprensiblemente, ha sido la piedra desechada. En efecto, lejos de presentarla como materia de conocimiento básico, la cultura ha quedado relegada a "actividades de divulgación" y estas, a su vez, se ofertan como algo complementario. A ello ha de sumarse la reducción notoria del peso específico de la formación de los profesionales y el incremento del de la investigación; siendo esta última la que se desarrolla exponencialmente sin parangón con los aspectos docentes y, aún otros más recientes tales como la gestión del empleo de los titulados, los contratos con empresas, la intervención en el campo de las residencias universitarias, etc.

Llegados a este punto y convencidos, como estamos, de que resulta preciso para la propia existencia de la Universidad reequilibrar sus funciones a partir de los valores de uso y de cambio del conocimiento, resta abordar la más compleja de las cuestiones; id est: cómo

\footnotetext{
${ }^{54}$ Concretamente nos referimos a su ensayo publicado bajo la rúbrica Misión de la Universidad, que vio la luz por primera vez en 1903. La edición que nosotros hemos leído es la de Santiago Fortuño Llorens, publicada por la editorial Cátedra. Letras Hispánicas, Madrid, 2015.

${ }_{55}$ Para un mayor abundamiento sobre esta temática, recomendamos la visualización de la Ponencia que ofreció el Profesor dominico Juan Manuel Almarza en el marco del Congreso “Alma Mater” de Salamanca celebrado en mayo de 2016 y cuyo enlace de seguida se facilita: https://www.domuni.eu/es/investigacion/recursos-en-linea/?order_by=titulo, [último acceso a fecha de 01/08/2020].

56 Concretamente sobre la Universidad humboldtiana y sin entrar en comparaciones con la Imperialnapoleónica se ha tenido ocasión de reflexionar por parte del Profesor Villa Pacheco en su "Sobre el lugar común: La Universidad humboldtiana puede ser correcta en teoría, pero no vale para la práctica. Una breve introducción a tres textos de Humboldt sobre la Universidad", Logos. Anales del Seminario de Metafísica, vol. 38, 2005, pp. 273-281.

${ }^{57}$ El análisis situacional se realizó en 2005 por el Catedrático de Química Analítica de la Universidad de Málaga José Manuel Cano Pavón: "La "Misión de la Universidad" de Ortega y Gasset setenta y cinco años después", publicado en: https://riuma.uma.es/xmlui/bitstream/handle/10630/932/Cano\%20Pavón\%2C\%20JM.pdf?sequence=1, [último acceso a fecha de 21/07/2020].
} 
contribuir a este logro. En este sentido, sin desconocer la pequeñez de nuestra capacidad y sin falsear las limitaciones que poseemos -puesto que este es otro de los males endémicos de la Universidad a juicio de Gasset-, un paso en la dirección apuntada puede constituirlo la elaboración de esta propuesta docente, puesto que a partir suya bien podría empezar a construirse el balance descrito. Con esta finalidad, en su diseño debe sustituirse al homo laborans, devolviendo al centro de la enseñanza universitaria la condición humana ${ }^{58} \mathrm{de}$ los sujetos participantes y del entero proceso de aprendizaje. Entendiendo el papel de los primeros como Arendt lo hizo, es decir, como sujetos activos de la sociedad que habitan y no sólo destinatarios de lo que otros -normalmente la clase política- entienden que necesitan.

En esta correlación de ideas, el siguiente paso que debe afrontarse, como consecuencia de la propia inercia del discurso generado, conduce irremediablemente a afrontar tanto el papel del alumno en la Universidad, el del docente y el del proceso de aprendizaje, puesto que irresolublemente están conectados. En este sentido, si hemos anotado con anterioridad que el del discente ha ser un rol activo, la consecuencia derivada para el docente es que debe permitir que así sea. Ello exige una actitud no sólo transmisora de conocimientos sino potenciadora de capacidades $\mathrm{y}$, además, respetuosa con las condiciones peculiares del alumnado sin perder de vista que estamos ante alguien deseoso de aprender.

Este deseo se presume, obviamente, en la educación superior que, al no ser obligatoria, permitiría que sólo los interesados se aproximasen a las aulas y al conocimiento en ellas generado. Ahora bien, cómo se haya de avivar y conservar este deseo, incluso, incrementándolo es una cuestión a la que parece haber dado respuesta la neuro-educación ${ }^{59}$. Esta, apoyada en los postulados de la psicología constructivista, parte de la meta-cognición -es decir, abundar en el proceso del "aprender a aprender"- en la que el aprendizaje ha de ser una forma de descubrimiento -presentándose por el docente las herramientas necesarias al alumnado de forma que le permitan descubrir lo que tiene que aprender, siendo así la emotividad el motor de la curiosidad-; el aprendizaje, además, debe estar contextualizado -de forma que pueda utilizarse y a la vez motivar acerca no sólo de su utilidad sino también del interés por continuar aprendiendo-; debe ser significativo -asentándose los nuevos conocimientos en otros preexistentes- $\mathrm{y}$, finalmente, que el alumnado asuma y sea consciente de su papel activo en su propio proceso de aprendizaje.

Estos cuatro puntos, como se infiere, perfilan el papel del alumnado, pero también el del docente y el del propio proceso de aprendizaje, de manera que, para ser coherentes con el discurso que planteamos, corresponde que su materialización sea trasladada tanto a esta propuesta como al quehacer diario en las aulas de la Facultad de Derecho.

En lo que corresponde al primero de los aspectos antes mentado, el relativo a la elaboración de la propuesta docente de manera concordante con las que hemos presentado como funciones clave de la Universidad en la sociedad y en la enseñanza y, por consiguiente, en la determinación del papel del discente, del docente y del proceso de enseñanza-aprendizaje, querríamos advertir sobre la influencia que en el planteamiento de este ensayo ha jugado el propio EEES y cómo ha podido utilizarse para, desde él, fortalecer

\footnotetext{
${ }^{58}$ Esta distinción y las características de uno y otro han sido objeto de lectura y reflexión a partir del ensayo de Hannah Arendt: The Human Condition, Chicago University Press, Chicago, second edition, 1998. Aunque dedicado al papel del hombre en la sociedad de la Segunda Guerra Mundial resultan de actualidad algunas de las afirmaciones allí contenidas como, por ejemplo, la de devolver a la humanidad su capacidad de acción en política para responsabilizarse de las derivas totalitarias.

${ }^{59}$ Son abundantes los estudios en este sentido, si bien a nivel superior nos atrevemos a citar a Francisco Mora Teruel: Neuro-educación. Sólo se puede aprender aquello que se ama, Alianza Editorial, Madrid, 2013.
} 
y dar cuerpo a nuestra particular visión de la Universidad en la educación y en la sociedad buscando el equilibrio entre valor de uso y de cambio del conocimiento. Para ello, hemos rescatado los aspectos del Plan Bolonia que conforme a estos valores del conocimiento permitan una doble lectura y que en la actualidad configuran la Guía Docente de la asignatura Derecho del Trabajo y de la Seguridad Social en el Grado en Derecho de la Universidad de Málaga. Tales aspectos son la enseñanza, el aprendizaje y la evaluación de competencias, de un parte y, de otra, la internacionalización de la Universidad y su conversión en un nódulo de la red europea de Universidades que sustituya la "fuga de cerebros" por "su circulación" a partir del fomento de la movilidad estudiantil y docente.

Cierto es que el Plan Bolonia ha perfilado hasta extremos insospechados los planes de estudio universitarios, el contenido de las áreas de conocimiento, su temporalización e incluso, su peso, con las finalidades expresamente reconocidas de fomentar la empleabilidad del ciudadano europeo, de fortalecer su movilidad y, por consiguiente, nutrir al mercado único de abundante y cualificada mano de obra. Sin embargo, no es menos verdad que esa movilidad -favorecida o mejorada por el reconocimiento profesional y académico- permite contribuir a la construcción de la cohesión y el bienestar social, mediante la libertad de circulación -no sólo de trabajadores, sino también de ciudadanoslo que refuerza el propio concepto de ciudadanía, las libertades que lleva aparejadas, el Pilar Europeo de Derechos Sociales ${ }^{60}$ y la integración social. Este último aspecto resulta de especial relevancia porque, desde el principio jurídico de reconocimiento mutuo de los Estados miembros, se garantiza la aceptación de las diversas culturas que convergen en el crisol que es Europa. Y, recordemos, la cultura es el sustrato de la Universidad y su preservación garantiza la de la propia institución universitaria.

Pues bien, auspiciado por esta posible doble lectura de cada actuación europea, la apuesta del EEES por la formación en competencias o capacidades deja a la academia un importante espacio de libertad que, a nuestro juicio, debe ser utilizado para continuar cultivando la condición humana del entero proceso de aprendizaje, de los sujetos implicados y, por tanto, para reequilibrar los valores de cambio y de uso del conocimiento. Este espacio se nos antoja el contexto ideal para implementar el aprendizaje constructivista $^{61}$, puesto que, recordemos, a partir de la enseñanza de competencias se recupera una de las dinámicas propias de la Unión europea: facilitar mecanismos de diálogo entre instituciones nacionales sin modificar la cultura subyacente. Concretamente, en lo que ahora interesa, la educación universitaria y las propias Universidades. Por tanto, para que la Universidad de Málaga se convierta en otro de los nódulos de la red europea de Universidades -para participar así de y en la movilidad y la circulación del conocimientoel EEES exige no sólo que se forme al alumnado en competencias, sino que sea posible su internacionalización -y la de los docentes- a través de la enseñanza multilingüe. Es decir,

\footnotetext{
60 La información al respecto puede leerse a través del enlace: https://ec.europa.eu/commission/priorities/deeper-and-fairer-economic-and-monetary-union/europeanpillar-social-rights/european-pillar-social-rights-20-principles_en, [último acceso a fecha de 21/07/2020]. Y, en concreto el texto, está disponible a través del enlace: https://ec.europa.eu/commission/sites/betapolitical/files/social-summit-european-pillar-social-rights-booklet_es.pdf, [último acceso a fecha de 21/07/2020]. Respecto de las causas y consecuencias de este Pilar se recomienda la lectura de los trabajos de la Profesora Margarita Isabel Ramos Quintana: "El Pilar Europeo de Derechos Sociales: la nueva dimensión social europea", Revista de Derecho Social, no 77, 2017, pp. 19-42 y, "El "momento cumbre" del pilar europeo de derecho sociales", Trabajo y Derecho: Nueva Revista de Actualidad y Relaciones Laborales, $\mathrm{n}^{\circ}$ 37, 2018, pp. 8-11.

${ }^{61}$ Las primeras alocuciones en España a este tipo de aprendizaje proceden de la obra de Jean Piaget, siendo la más consultada a estos efectos la rubricada Memoria e Inteligencia. Nosotros hemos consultado la edición publicada en 1978 por la editorial El Ateneo, Madrid.
} 
que se ofrezca un proceso de aprendizaje en lengua distinta al castellano que, al convertirse en lengua vehicular del conocimiento de instituciones propias españolas, permita no sólo recibir alumnos de otras Universidades europeas e internacionales, sino que estos se aproximen a nuestra cultura jurídica, así como formar al alumnado español en esta competencia transversal instrumental para que también ellos puedan aproximarse a otras culturas jurídicas o intercambiar ideas respecto de la propia. La imposición de la enseñanza bilingüe de asignaturas de contenido jurídico como esta que referimos en nuestra propuesta, por tanto, pretendemos transformarla en una oportunidad inclusiva como de seguida se presenta.

\subsection{Hacer de la imposición del inglés una oportunidad inclusiva a partir del aprendizaje constructivista.}

La impartición de docencia en lengua distinta de la propia en absoluto es un fenómeno del siglo XX. Durante la Edad Media y en el Renacimiento las universidades europeas acudían al latín como lengua vehicular ${ }^{62}$ tanto para la transmisión de conocimientos vía oral como para la edición de sus publicaciones, rechazando la utilización de las lenguas vernáculas.

Salvando las distancias temporales y las posibilidades de elección que en la actualidad efectivamente existen, lo trascendente del dato es que antes y también ahora se trataba, se trata, de lenguas dominantes, casi tiranas, porque emanan de unos pueblos que de este modo se relacionan con el resto. El latín, procedente de Roma, era hegemónico en el mundo occidental porque era romano el imperio del único mundo conocido, mientras que el inglés, promovido por Estados Unidos ${ }^{63}$, es hegemónico en el mundo occidental porque es Estados Unidos la principal potencia económica mundial. Por consiguiente, que de entre las 7097 lenguas actualmente reconocidas en el mundo ${ }^{64}$, se proclame al inglés como "idioma de la globalización" 65 no es un descubrimiento y tampoco una aberración. Es, sencillamente, constatar un hecho desde el que comenzar a formular nuestra propuesta siendo este el motivo por el cual hemos tratado de reflejarlo en la rúbrica de este apartado al utilizar de forma consciente el sustantivo "imposición". Mientras que, la otra parte del la título, sin embargo, refleja el uso personal que de aquella presión socio-económica pretendemos hacer en nuestro propio diseño docente, convirtiéndola en una oportunidad de inclusión laboral y social, en la medida en que permitiría capacitar al alumnado para conocer otras culturas -también jurídicas- y dar a conocer la propia a partir de estructuras mentales que, al ser ajenas, lo introducen en una interesante dinámica de alteridad ${ }^{66}$ que, a la postre, redunda en su capacidad para integrar y para ser integrado.

\footnotetext{
62 Recuperado del trabajo de la Profesora María Ángeles Martín Del Pozo: "Formación del profesorado universitario...", op. cit., pág. 199.

${ }^{63}$ No referimos el mundo anglosajón porque no todos los países de este ámbito tienen el potencial económico que el demostrado por Estados Unidos.

${ }^{64}$ Así se indica en el artículo periodístico publicado el 21/02/2019 por la Revista Ethnologue disponible en la web: https://www.europapress.es/sociedad/noticia-idiomas-cifras-cuantas-lenguas-hay-mundo20190221115202.html, [último acceso a fecha de 21/07/2020].

${ }^{65}$ Este es el axioma de partida del V Congrés Internacional sobre Llengües per a Finalitats Específiques, celebrado en Canet de Mar, los días 6, 7 y 8 de septiembre de 2001 y cuyas actas se publicaron bajo el formato de libro, editadas por la Universidad de Barcelona bajo la supervisión de la Profesora Frances Luttikhuizen. ${ }^{66} \mathrm{La}$ dinámica de alteridad en el ámbito jurídico en general y en el laboral en particular ha sido abundantemente tratada por el Profesor Márquez Prieto entre otros en su Repensar la Justicia Social. Enfoque relacional, teoría de juegos y relaciones laborales en la empresa, Thomson Reuters Aranzadi, 2008, pág. 75.
} 
Plantearse el uso del inglés -o de cualquier otra lengua extranjera- como instrumento de aprendizaje requiere partir de una formulación que, no por ser básica, deja de resultar importante recordar. Y es que el inglés -o el idioma de que se trate- se utiliza como una herramienta -entendida en su acepción más estricta- para aprender contenidos que en absoluto son idiomáticos. Por ello, esta técnica de aprendizaje se suele identificar como EMI (English as a Medium of Instruction) o en castellano AICLE (Aprendizaje Integrado de Contenidos en Lengua Extranjera). En este sentido, el profesor no tiene que enseñar lengua inglesa -aunque sí debe prestar atención a cómo la usa en el aula- ${ }^{67}$, sino que el inglés genera un especial entorno de aprendizaje que exige un doble esfuerzo al discente y al docente: de un lado, aproximarse al contenido de la materia que efectivamente se estudia -en nuestro caso Derecho del Trabajo y la Seguridad Social-; y, de otro, que esa aproximación se haga desde unos esquemas mentales e idiomáticos que no son los propios. Este concreto procedimiento que implica aprender, expresarse o estudiar en otro idioma exige abandonarse -en el sentido de olvidar o apagar temporalmente las habituales estructuras mentales y discursivas- para poder dejar paso a otras diseñadas por el nuevo idioma y por las nuevas estructuras mentales y discursivas que este arrastra. No se trata de que el alumnado o el profesor nacionales entren en una suerte de dinámica al estilo "doctorjekyll-\&-mister-hide", pero sí que afronten el desafío de observar con gafas nuevas una realidad que comienza a conocerse para entenderla, poder demostrar que se ha aprendido en la fase de la evaluación- y transmitirla -llegado el momento del ejercicio profesional o del intercambio con otros compañeros internacionales-.

Este doble proceso de aprendizaje en la materia que nos ocupa -mezclando las estructuras formales idiomáticas con las sustanciales jurídicas- $\mathrm{y}$, aunque en general, en la Universidad española, adolece de un adecuado proceso de evaluación y valoración de resultados ${ }^{68}$, permitiría, a nuestro juicio, alcanzar un objetivo que sobrepasa las archiconocidas metas del incremento de la empleabilidad o de la internacionalización sea de la Universidad, sea de alumnos y profesorado (propios o extranjeros), más próximas al valor de cambio del conocimiento. Se trataría de contribuir a entender las disciplinas jurídicas desde la posición nueva en la que ubica un idioma distinto al propio. Ello no conlleva modificar un ápice el contenido de la materia, pero sí la posición del discente y la del docente en la medida en que ambos se enfrentan al mismo desafío: comunicar y expresar en una lengua distinta a la propia con las dificultades que ello supone. Precisamente estas dificultades que suelen surgir tanto en el plano de la comprensión mutua como en el de la interacción tienen como consecuencias las siguientes: de un lado, flexibilizan las actitudes ${ }^{69}$ de los sujetos implicados puesto que, condenados a entenderse, deben esforzarse -tal vez en mayor grado que en las clases impartidas en castellano- por comprender y ser comprendidos. De otra parte y, como consecuencia de lo anterior, aumenta el nivel de atención -especialmente el de los discentes- respecto a la forma y al contenido de lo que trata de transmitir el docente. En tercer lugar, del lado del docente, se toma una clara conciencia de los elementos que pueden dificultar la comprensión -por ejemplo, el uso de metáforas, del lenguaje figurativo, los juegos de palabras, etc.- y, especialmente cobran una relevancia esencial las referencias culturales. Estas, justamente, en el ámbito jurídico laboral son esenciales para poder aplicar de forma adecuada la terminología anglosajona puesto que, el inglés, aun siendo utilizado exclusivamente como

67 Recuperamos aquí la reflexión que introduce la Profesora Martín Del Pozo: "Formación del profesorado...", op. cit., pág. 200.

${ }^{68}$ Ibídem, pág. 204.

${ }^{69}$ Un análisis en este sentido ha sido recogido en el estudio de Matthew Johnson: "Bilingual Degree Teacher's Beliefs: A case study in a tertiary setting", Pulso. Revista de Educación, n 35, 2012, pp. 49-74. 
lengua vehicular, está cargado y sostenido por la propia cultura de la que procede. De manera que, en su uso para denominar, para etiquetar instituciones jurídicas propias españolas, habrá de tenerse presente las distancias existentes entre la cultura de procedencia y la de destino y evitar así "entrar como elefante en cacharrería", generando mayor oscuridad que luz. En este punto, se hace esencial retomar las reflexiones orteguianas para avivar la importancia de conocer y tener claras las ideas pertenecientes a una y a otra cultura, puesto que de ello se deriva que puedan estructurarse de forma adecuada tanto la temporalización como el contenido de cada clase. Tomemos como ejemplo, en este sentido, un sencillo término como puede ser el de trabajador por cuenta ajena. De conformidad con el artículo 1.1 ET lo es, en el ordenamiento jurídico español, quien presta servicios por cuenta de otra persona, de forma voluntaria, libre remunerada y bajo su ámbito de dirección. El desconocimiento -o conocimiento parcial- de las referencias culturales y jurídicas que el término worker contiene y significa en el ámbito anglosajón, podrían llevar a traducir o intercambiar sin mayores explicaciones un concepto por otro, aunque evocan realidades distintas y no equiparables.

En este contexto, podríamos decir que discentes y docentes están súper motivados, puesto que conscientes no sólo de la doble dificultad que entraña conciliar el aprender Derecho del Trabajo a partir de la lengua inglesa, sino de la importancia de respetar las referencias culturales evocadas, sea por el idioma sea por el contenido de la asignatura que se enseña, se generan unas concretas dinámicas interactivas. Estas incidirían favorablemente en la relación docente/alumno -que asume un mayor protagonismo por aumentar la interdependencia comunicativa- y también en la calidad ambiental ${ }^{70}$ de la red de relaciones existente en el grupo de la clase, además de habituar a los implicados a trabajar con unos específicos esquemas mentales que, por exigencias de la propia dinámica del proceso de aprendizaje, contribuirán a su mayor elasticidad y apertura hacia la aceptación "del otro" y de "lo otro" sin modificarlo, lo que redunda en su capacidad para integrarse y de integración. Es decir, a considerar "al otro" y a "lo otro" -entiéndase, los alumnos procedentes de otros países, los otros idiomas, las otras culturas jurídicas- como alguien o algo distinto, pero a la vez, partes inextricables del todo que es la realidad y de la que "el yo" o "lo mío" -léase, la cultura jurídica española, el castellano, etc.- son sólo otras de las partes. Siendo lo otro y lo mío dignos de un trato equiparado y equiparable.

Experimentada así la vivencia de la alteridad, la docencia de la asignatura Derecho del Trabajo y de la Seguridad Social en lengua inglesa se antoja el caldo de cultivo perfecto para presentar una de las tres finalidades reconocidas al Derecho en general y que, específicamente en su rama laboral, alcanzaría unas más elevadas cotas de desarrollo: nos referimos a su función integradora. Esta finalidad, a diferencia de la ordenadora de la sociedad y la reguladora de conductas, apuntaría a la capacidad que encierra el Derecho del Trabajo para, a partir del Derecho Vivo y, sin olvidar su función tuitiva, ser expediente de inclusión ${ }^{71}$-que no de inserción si nos dejamos guiar por la diferencia de significados ${ }^{72}$ a ellos vinculados atendiendo a la perdurabilidad y rotundidad de la primera frente a lo coyuntural de la última-. Y ello, en la medida en que, sin desconocer la existencia del conflicto y la legitimidad de los intereses distintos, es capaz de conciliar en sí la pluralidad

\footnotetext{
${ }^{70}$ El concepto de calidad ambiental y su significancia han sido utilizados en este trabajo a partir del sentido que le otorga el Prof. Márquez Prieto en su Calidad Ambiental de las Relaciones Laborales. Ensayo Interdisciplinar, Comares, 2011.

${ }^{71}$ Esta reflexión procede del primero de los ensayos que sobre esta temática ha elaborado el Prof. Márquez Prieto: Repensar la Justicia Social..., op. cit., pág. 78.

${ }^{72}$ Esta reflexión, a través del mito de Sísifo, la introduce Robert Castel en la página 157 de su Las Metamorfosis de la Cuestión Social. Una crónica del salariado, Paidós, Buenos Aires, 1997.
} 
de partes y de sus respectivas motivaciones - contrapuestas, la mayor parte de las vecesque se dan encuentro en las relaciones productivas. Esta otra aproximación al ámbito jurídico-laboral no supone sustituir los contenidos sobre los que se asienta la asignatura referida, sino, sencillamente abordarlos y presentarlos enfatizando la trascendencia que asume la relación intersubjetiva que sostiene la relación jurídica laboral y la búsqueda a través suya de la justicia, tal y como propone el enfoque de Justicia relacional ${ }^{73}$. De este modo nos encontraríamos ante dos dinámicas integradoras paralelas que redundan no sólo en el valor de cambio del conocimiento generado, sino también en el de su uso: la creada por la propia dinámica inclusiva del proceso de aprendizaje que, partiendo del reconocimiento de las dificultades surgidas para enseñar y aprender en otro idioma una realidad próxima, permitiría a sus participantes ensayar y materializar técnicas de apertura y aceptación -o, al menos, tolerancia- respecto de la existencia de otros esquemas culturales de pensamiento y de discurso, reconociéndolos -tratándolos y respetándolos- como partes del todo que es la realidad. Lo que posibilitaría aprender competencias específicas jurídicas, pero también transversales interpersonales tales como el trabajo en equipo y en contextos internacionales. Por otra parte, al experimentar esa apertura hacia lo distinto podría aumentar la motivación del alumnado para aproximarse cognoscitivamente al Derecho del Trabajo y también a esta específica función como verdadero expediente de integración. La cual, para una mejor comprensión de las innovaciones que introduce en la práctica docente y en el contenido de la asignatura, requiere que de seguida se presenten cuáles son y cómo se han ordenado las actividades que han configurado la docencia en inglés de esta asignatura jurídica.

En su diseño se ha tratado seguir las pautas marcadas por el aprendizaje constructivista de ahí que los criterios de evaluación se hayan diseñado para hacerse eco de esta especialidad; de manera que, sin perder de vista la importancia de retener contenidos, también han de valorar la adquisición de las competencias conectadas con la capacidad lingüística, el trabajo en equipo o la capacidad de desenvolverse en contextos jurídicos internacionales. Así como utilizar distintos métodos de evaluación que abarcan desde pruebas de conocimiento consecutivas, la defensa de distintas posturas en los supuestos planteados a través de juegos de role-play o simulación, la exposición de temas en clase, la localización de concretos términos técnicos en lengua inglesa a partir de convenios internacionales y normativa comunitaria y el uso de específicos programas informáticos tales como LexNET y buscadores oficiales nacionales y comunitarios de normativa y jurisprudencia para su interpretación.

En la confección de tales procedimientos ha de tenerse en cuenta en primer lugar, la aprobación por parte de la Universidad de Málaga a través del Consejo de Gobierno en su sesión celebrada el 23 de julio de 2019, de la normativa reguladora de los procesos de evaluación de los aprendizajes, conforme a la cual el criterio inspirador de estos es la evaluación continua del estudiante -artículo 1.3-. Ello conlleva que sea como fueren o consistan en lo que consistieren los concretos procesos deben obedecer a esta máxima.

En segundo lugar, también es necesario referir las excepciones existentes al respecto, conectadas con el momento temporal en que el alumno sea evaluado, dado que existen dos convocatorias ordinarias, una extraordinaria y otra "fin de estudios". Por tanto, la evaluación continua es posible realizarla sólo si los discentes son evaluados en primera convocatoria ordinaria. En el resto, la única vía posible es la del examen final, con independencia de que este pueda consistir en el desarrollo escrito u oral de preguntas de teoría, tipo test y/o la resolución de casos prácticos -estos últimos con o sin apoyo material

\footnotetext{
${ }^{73}$ De nuevo, Antonio Márquez Prieto en Repensar la Justicia Social..., op. cit.
} 
normativo-. A esta misma modalidad está previsto que se acojan los estudiantes a tiempo parcial y los deportistas de alto nivel que no puedan seguir el sistema de evaluación continua.

Para estos concretos casos, proponemos la realización de un cuestionario tipo test compuesto por 140 preguntas, a razón de 10 preguntas por cada tema, clasificadas en tres niveles de dificultad -mínimo, referido a sencillas cuestiones para elegir la opción verdadera, medio, en que habrán de elegir la opción verdadera o falsa y máximo, donde las preguntas son pequeños casos prácticos- cuya respuesta incorrecta no descuenta y, con un plazo de tiempo para su realización de 140 minutos. El desarrollo de este cuestionario será presencialmente si las condiciones sanitarias lo permiten o bien, virtualmente en caso contrario.

Dada la circunstancia de que los alumnos sí puedan seguir el sistema de evaluación continua, las actividades evaluables consistirán en la realización de dos debates -0.5 puntos como máximo obtenido en cada uno-, la resolución individual de tres casos prácticos -1 punto como máximo obtenido tras la realización de los tres supuestos-, la participación en tres simulaciones -1 punto como máximo en cada una- y la realización de tres pruebas tipo test -5 puntos como máximo obtenidos de la suma de las calificaciones alcanzadas tras la realización de todas ellas-.

En lo que respecta a los debates -debates- y aunque pueden considerarse otra forma de simulación $^{74}$, en nuestra propuesta los hemos distinguido de esta en la medida en que por el momento temporal en que está previsto su desarrollo los alumnos no necesitan de amplios conocimientos jurídicos. Nuestro propósito, por tanto, al incluirlos de forma tan temprana en la asignatura es preparar el terreno -actitudinal, mental y cognoscitivo- para las profundidades que habrán de alcanzarse con las simulaciones. De modo que se inicie la generación de esas dinámicas de alteridad que, con posterioridad, serán fundamentales para comprender y aplicar la función integradora del Derecho del Trabajo. Por otra parte, ha de mencionarse que con esta propuesta buscamos, también, trabajar en el aula competencias referidas tanto a la lengua vehicular -en sus dimensiones comprensivas y expositivas- como el manejo de fuentes jurídicas, la lectura y la interpretación de textos jurídicos, el dominio de técnicas y red informáticas y el desarrollo de una conciencia crítica en el estudio del ordenamiento jurídico. Para ello el primero de los debates, a celebrar el primer día de clase, se centra en un sencillo ejercicio, más aproximativo que formativo, a la disciplina laboral. Así, el ejercicio/debate denominado "Choose one!!" propone que los alumnos recién llegados al aula y a la asignatura elijan, de forma individual, un determinado contexto histórico de entre los tres propuestos -la Grecia clásica, la Edad Media y la Primera Revolución Industrial- y, en el escogido, desempeñar un concreto papel relacionado con el mundo del trabajo en general -ser esclavo en el primero, siervo en el segundo y proletario en el último-. De esta forma y aun sin mayores nociones, pretendemos que reflexionen sobre las implicaciones, ventajas y desventajas del trabajo por cuenta ajena como mecanismo de subsistencia, participación socio-económica y desarrollo personal. El segundo de los debates - European Employment Policies Discussions- está previsto que se implemente aproximadamente en la quinta semana de docencia, de forma que algunas competencias relativas a la dinámica propia del ámbito laboral habrían sido ya adquiridas.

\footnotetext{
${ }^{74}$ Son escasos los estudios al respecto de la organización y diseño de actividades de simulación en las aulas en que se imparten asignaturas jurídicas y, aun menos, de contenido específicamente laboral. Precisamente, en este sentido y distinguiendo los debates de la simulación o dramatización, el Prof. José Manuel Morales Ortega es la excepción a esta parquedad con dos estudios recientes en este sentido. Se trata del capítulo de libro "Relaciones Laborales en la empresa: negociación...", op. cit., pág. 150; y de artículo "Dramatización del conocimiento...", op. cit., pág. 93.
} 
En esta segunda ocasión, se pretende que los alumnos, en grupos de tres personas, se acerquen a la política de empleo de los países miembros de la Unión Europea, de manera que pueda trabajarse tanto la competencia relativa al trabajo en equipo, como el aprendizaje autónomo en la medida en que son ellos quienes han de buscar los materiales sobre los Planes Nacionales de Acción, la Estrategia Europea de Empleo y las Orientaciones que anualmente plantea la Comisión. La finalidad es, pues, que amplíen tanto el vocabulario en esta específica área de estudio, el papel de la UE en esta materia, como los conocimientos generales sobre actuaciones específicas en los distintos países miembros. De esta forma se espera que se adquieran nociones sobre las buenas prácticas, las posibilidades de su implementación en el mercado de trabajo español, así como el pensamiento crítico.

La resolución de los tres supuestos prácticos -cases of study- se hará de forma individual por cada alumno, habiendo sido planteado cada caso a partir de sentencias y hechos probados procedentes de la jurisprudencia española, pudiendo los discentes consultar los materiales normativos y jurisprudenciales que consideren necesarios. Para ello se les mostrará la existencia de distintos buscadores de normativa y de jurisprudencia tanto a nivel nacional, europeo e internacional. De esta forma se incide en el ejercicio de las competencias relacionadas tanto con la capacidad para entender y expresarse en otra lengua, en el trabajo autónomo, en el manejo de fuentes jurídicas, en la lectura e interpretación de textos jurídicos y en el dominio de las técnicas y red informática.

Las simulaciones -simulations- o dramatizaciones, por su lado, están configuradas en un número de tres y se ubican tras la realización de los correspondientes supuestos prácticos individuales. En ellas participa la totalidad del grupo clase, si bien dividido en grupos en función de los roles a desarrollar, como de seguida se indica, los cuales además serán de obligatorio intercambio; es decir, quienes han sido empleadores, pasarán a Poder Público, quienes hayan asumido el rol de trabajadores pasarán a empleadores, etc. Con la finalidad de graduar su nivel de dificultad, en la medida en que se trata de un ejercicio que posee cierta complejidad y porque al alumnado le supone un 30\% del total de su calificación final, la primera de ellas consistiría en la presentación por parte del docente de una noticia periodística relacionada con el mundo del trabajo por cuenta ajena -shocking news story-. En esta concreta simulación aparecen tres roles bien identificados: empresario, trabajador y, Poderes Públicos -Administración Laboral, Legislador, Ejecutivo, etc-. En el grado medio se procurará presentar una cuestión prejudicial -preliminary question- elevada al TJUE y relacionada con algún tema especialmente conflictivo y relevante. De nuevo es necesario distinguir al tribunal, al Estado que eleva la cuestión y a las partes afectadas. El nivel más elevado de dificultad consistirá en la simulación de la doble vía para la resolución de un conflicto colectivo -collective conflict- relacionado con alguna empresa de la localidad, la Autonomía o el Estado; siendo en estos casos necesario recurrir a cuatro partes: empresario/s, trabajador/es, comisión paritaria y mediador o árbitro. Tal y como la doctrina ${ }^{75}$ apunta al respecto de la utilización de estas técnicas, al prescindir el docente de dar indicaciones claras -tales como preguntas en cualquiera de sus formas- se desarrolla especialmente la competencia relativa al aprendizaje autónomo, sin olvidar el resto de competencias transversales instrumentales -tales como el trabajo en equipo, el trabajo en un contexto internacional, la capacidad para conocer y expresarse en una lengua extranjeray aquellas otras específicas -que abarcan desde el manejo de fuentes jurídicas, la interpretación de textos jurídicos, el uso de la red y las técnicas informáticas y la identificación del papel de los operadores jurídicos en las relaciones laborales-. Para su preparación se hace obligatorio para el docente presentar desde el primer día de clase la

\footnotetext{
${ }^{75}$ De nuevo Morales Ortega en su "Dramatización del conocimiento...", op. cit., pág. 95.
} 
temporalización de todas las actividades, pero especialmente de estas, puesto que, en ellas, el diálogo y la empatía son estructurales ${ }^{76}$. Con esta actividad final se pretende insertar al alumno en la dinámica no sólo negociadora, sino en el expediente de inclusión que el Derecho del Trabajo supone de manera que, a partir de la experiencia de la negociación, de la transacción y de la alteridad, se aprenda a ver con otros ojos el mundo productivo y laboral.

Finalmente, la secuenciación de los tres test se realizaría al fina de cada bloque temático, estando compuestos cada uno por un total de 10 preguntas por tema o lección y cuya disposición se hará entorno a tres niveles de dificultad, con idénticas especificaciones a las realizadas para el caso de alumnos que no sigan el sistema de evaluación continua. El alumnado dispondrá de un máximo de 1 minuto para responder cada pregunta.

\section{Bibliografía.}

- ARENDT, HANNAH: “The Human Condition", Chicago University Press, Chicago, second edition, 1998.

- CANO PAVÓN, JOSÉ MANUEL: "La "Misión de la Universidad” de Ortega y Gasset setenta y cinco años después", publicado en: https://riuma.uma.es/xmlui/bitstream/handle/10630/932/Cano\%20Pavón\%2C\%20JM.p $d f$ ? sequence $=1$, [último acceso a fecha de 21/07/2020].

- CASTEL, ROBERT: "Las Metamorfosis de la Cuestión Social. Una crónica del salariado", Paidós, Buenos Aires, 1997.

- FIGUERAS, NEUS: "El Marco común europeo de referencia para las lenguas: de la teoría a la práctica", Carabela 57, febrero 2005, pp. 5-23.

- GARCÍA AÑÓN, JOSÉ: "Los estudios de derecho en Europa y la reforma de los planes de estudio: reflexiones y propuestas" en GARCÍA AÑÓN, JOSÉ (Coord.): Los estudios de Derecho en Europa: Alemania, Francia, Italia, Reino Unido e Irlanda, Universidad de Valencia, 2008, pp. 1-47.

- GARCÍA SAN PEDRO, MARÍA JOSÉ: "Evaluar la integración de las competencias en la universidad: hoja de ruta para evaluar la integración efectiva de las competencias en los programas formativos y orientarla hacia la mejora", Mensajero, Bilbao, 2013.

- GARCÍA SANTA-CECILIA, ÁLVARO: "Bases comunes para una Europa plurilingüe. Marco común europeo de referencia para las lenguas" en VV.AA.: El español en el mundo. Anuario del Instituto Cervantes, Plaza-Janés y Círculo de Lectores, Barcelona, 2002.

- HABERMAS, JÜRGEN: “The Lure of Technocracy”, Polity Press, London, 2015.

\footnotetext{
76 También de José Manuel Morales, pero en su "Relaciones Laborales en la empresa: negociación...”, op. cit., pág. 149.
} 
- HALBACH, ANA; LÁZARO LAFUENTE, ALBERTO y PÉREZ GUERRA, JAVIER: "La Acreditación del Nivel de Lengua Inglesa en las Universidades Españolas", Bristish Council, marzo, 2010, pp. 1-35.

- JOHNSON, MATTHEW: "Bilingual Degree Teacher's Beliefs: A case study in a tertiary setting", Pulso. Revista de Educación, no 35, 2012, pp. 49-74.

- LÓPEZ ALÓS, JAVIER: “Crítica de la razón precaria. La vida intelectual ante la obligación de lo extraordinario", Libros de La Catarata, Madrid, 2019.

- LUTTIKHUIZEN, FRANCES (Ed.): "V Congrés Internacional sobre Llengües per a Finalitats Específiques", Universidad de Barcelona, Barcelona, 2002.

- MÁRQUEZ PRIETO, ANTONIO: "Repensar la Justicia Social. Enfoque relacional, teoría de juegos y relaciones laborales en la empresa", Thomson Reuters Aranzadi, 2008.

- "Calidad Ambiental de las Relaciones Laborales. Ensayo Interdisciplinar", Comares, 2011.

- MARTÍN DEL POZO, MARÍA ÁNGELES: "Formación del profesorado universitario para la docencia", Revista de Docencia Universitaria, vol. 11 (3), Octubre-Diciembre 2013, pp. 198-215.

- MARTÍNEZ RODRÍGUEZ, JUAN BAUTISTA: "Evaluar las universidades como práctica social, política y ética: Crítica a la teoría de las competencias", Cuadernos para la Educación Superior, Año 2004, pp. 57-73.

- MORA TERUEL, FRANCISCO: "Neuro-educación. Sólo se puede aprender aquello que se ama", Alianza Editorial, Madrid, 2013.

- MORALES ORTEGA, JOSÉ MANUEL: "Dramatización del conocimiento: simulaciones en el contexto de los estudios jurídico-laborales de grado y de posgrado", REJIE, $\mathrm{n}^{\circ} 17,2018$, pp. 81-98.

- "Relaciones Laborales en la empresa: negociación, resolución de conflictos y gestión de personal. Un acercamiento desde la simulación" en SÁNCHEZ HERNÁNDEZ, CARMEN (Coord.): Aprendizaje colaborativo y técnicas de simulación, Tirant lo Blanch, Valencia, 2020, pp. 141-160.

- NOGUEIRA GUASTAVINO, MAGDALENA: "El constructivismo como base teórica del nuevo método docente y su proyección en los Estudios de Derecho del Trabajo", Revista de Derecho del Trabajo y de la Seguridad Social, núm. 27, 2011, pp. 1-32.

- ODRIOZOLA GUITART, SILVIA y COLINA HERNÁNDEZ, HENRY: "Aproximación marxista a la relación conocimiento-valor en la economía capitalista contemporánea", Textos \& Contextos (Porto Alegre), v. 15, n² 2, ago./dic. 2016, pp. 264274.

- ORTEGA Y GASSET, JOSÉ: “Misión de la Universidad”, edición de Santiago Fortuño Llorens, Cátedra. Letras Hispánicas, Madrid, 2015. 
- PATINO, BRUNO: "La civilización de la memoria de pez. Pequeño tratado sobre el mercado de la atención", trad. por Alicia Martorell Linares, Alianza Editorial, Colección Ensayos, Madrid, 2020.

- PIAGET, JEAN: “Memoria e Inteligencia”, El Ateneo, Madrid, 1978.

- RAMOS QUINTANA, MARGARITA ISABEL: "El Pilar Europeo de Derechos Sociales: la nueva dimensión social europea", Revista de Derecho Social, nº 77, 2017, pp. 19-42.

- "El "momento cumbre" del pilar europeo de derecho sociales", Trabajo y Derecho: Nueva Revista de Actualidad y Relaciones Laborales, n 37, 2018, pp. 8-11.

- SALAS PORRAS, MARÍA: "Las libertades de Circulación y Establecimiento de Trabajadores. Aportaciones para el Avance de la Dimensión Social Europea desde el Enfoque Transnacional", Thomson Reuters Aranzadi, 2019.

- SEN, AMARTYA: “The Idea of Justice”, Belknap Press, Neew York, 2011.

- TIERNO GARCÍA, JUANA MARÍA; IRANZO GARCÍA, PILAR y BARRIOS ARÓS, ROSARIO: "El compromiso organizativo e institucional para diseñar y evaluar competencias en la universidad", Revista de Educación, n 361, 2013, pp. 223-251.

- VILA TIERNO, FRANCISCO: "Utilización de herramientas informáticas para el uso de la profesión en Ciencia Jurídica: el caso concreto del sistema LexNET" en BURGOS GOYE, MARÍA DEL CARMEN; LÓPEZ INSUA, BELÉN DEL MAR (Coords.); SERRANO ESCRIBANO, SELINA (Dir.): Innovación docente en ciencias sociales y jurídicas: el reto de facilitar salidas profesionales desde el enfoque por competencias y capacidades, Ediciones Laborum, Murcia, 2019, pp. 137-152.

- "Una propuesta real de innovación docente: las lagunas formativas en materia de competencias en NNTT y herramientas telemáticas de uso procesal" en GÓMEZ SALADO, MIGUEL ÁNGEL Y GUTIÉRREZ BENGOECHEA, MIGUEL (Coords.): Nuevas necesidades docentes en las enseñanzas jurídicas, Ediciones Laborum, Murcia, 2019, pp. 29-48.

- VILLA PACHECO, BORJA: "Sobre el lugar común: La Universidad humboldtiana puede ser correcta en teoría, pero no vale para la práctica. Una breve introducción a tres textos de Humboldt sobre la Universidad”, Logos. Anales del Seminario de Metafísica, vol. 38, 2005, pp. 273-281.

- WEILER, JOSEPH H. H.: "The Constitution of Europe: Do the New Clothes Have an Emperor? "Cambridge University Press, 1999. 


\section{Anexo I.}

Propuesta de cronograma de la asignatura Derecho del Trabajo y de la Seguridad Social (docencia: lengua inglesa)

\section{Primera semana (del 15 al 19 de febrero)}

\section{Miércoles, día 17 de febrero (de 9 a 12:30 horas)}

- Introducción ("Getting to know each other") (15 min. aprox.): se trata de una sencilla actividad consistente en "romper el hielo" y fomentar desde el primer momento el sentido de pertenencia al grupo. De este modo esperamos que los alumnos no sólo pierdan o rebajen su sentido del ridículo hablando en inglés a pesar de hallarse en España y con compañeros, en su mayor parte, hispanoparlantes, sino que aprendan a dar el primer paso para entablar una conversación o una relación entre compañeros.

- Presentación de la asignatura (“Choose one!!”) (40 min. aprox.): Tras las respectivas indicaciones relativas a la Guía Docente de la asignatura, la utilización de la plataforma Moodle, la explicación atinente a la temporalización de las actividades, habrá de procederse a la explicación del apartado 1.1 (sobre el concepto, evolución histórica y caracteres del Derecho del Trabajo). En este momento y, puesto que los alumnos aún no han tenido tiempo material de aproximarse al contenido de la asignatura, el ejercicio de debate que se presenta es relativamente sencillo, consistiendo exclusivamente en elegir para vivir uno de los tres momentos históricos presentados y justificar por qué esa es la opción preferida de entre las siguientes: ser esclavo en la Grecia Clásica, siervo en la Edad Media o, proletario en la Primera Revolución Industrial.

- A partir de las conclusiones obtenidas en este debate se proseguirá con las explicaciones teóricas del apartado segundo hasta extinguirlo, procediendo a realizar una pausa de aproximadamente 20 minutos en torno a las 11 horas de la primera mañana de clase.

$\underline{\text { Viernes, día } 19 \text { de febrero (de 13:30 a 15:30 horas) }}$

- Se continúa con las explicaciones del apartado tercero del tema primero hasta agotarlo y tras una pausa de 10 minutos, se inicia el tema segundo.

\section{Segunda semana (del 22 al 26 de febrero)}

\section{Miércoles, día 24 de febrero (de 9 a 12:30 horas)}

- Continuación de las explicaciones del tema segundo y planteamiento de cuestiones al respecto para conocer el grado de comprensión del alumnado. Se trata de mini casos prácticos para responder en el mismo acto de la explicación, buscando que la clase magistral sea activa y dinámica.

- Resulta necesario conservar y repetir la pausa de los 20 minutos.

Viernes, día 26 de febrero (sin clase) 


\section{Tercera semana (del 1 al 5 de marzo)}

Miércoles, día 3 de marzo (de 9 a 12:30 horas)

- Se inicia la explicación del tema tercero, relativo a los principios de aplicación de las normas laborales.

- Tras el descanso, se presenta a los alumnos la actividad relativa al debate que se celebrará tras la explicación del tema 5. Formación de los grupos atendiendo al libre albedrío de los discentes. Se presenta también la página web que deben utilizar para formalizar sus posiciones -en representación de los Estados miembros elegidos y como Comisión europea-.

Viernes, día 5 de marzo (de 13:30 a 15:30 horas)

- Finalización de las explicaciones del tema tercero en la primera hora y media de clase. El resto del tiempo se destina al trabajo en equipo para preparar el debate sobre la European Employment Policies Discussions.

\section{Cuarta semana (del 8 al 12 de marzo)}

Miércoles, día 10 de marzo (de 9 a 12:30 horas)

- Inicio de las explicaciones teóricas respecto del tema cuarto sobre nociones básicas del derecho colectivo.

- Tras el tiempo de descanso se retoma el trabajo en equipo -especialmente para la resolución de dudas- dada la proximidad del debate sobre las políticas europeas de empleo de los Estados miembros de la UE.

Viernes, día 12 de marzo (de 13:30 a 15:30 horas)

- Finalización de las explicaciones del tema cuarto.

\section{Quinta semana (del 15 al 19 de marzo)}

Miércoles, día 17 de marzo (de 9 a 12:30 horas)

- Introducción por parte del docente de la organización temporal del debate: ¡qué comience el debate!

- Tras el descanso de 20 minutos, llega el momento de obtener conclusiones por parte del equipo de la Comisión europea y deben proponerse orientaciones...

Viernes, día 19 de marzo (de 13:30 a 15:30 horas)

- Resolución de dudas por parte del docente respecto del tema quinto y preparación para la realización del cuestionario.

\section{Sexta semana (del 22 al 26 de marzo)}

Miércoles, día 24 de marzo (de 9 a 12:30 horas)

- Realización del primer cuestionario (duración: 50 minutos). Corrección en clase.

- Descanso de 20 minutos. 
- Se inician las explicaciones relativas al tema sexto sobre el contrato de trabajo.

Viernes, día 26 de marzo (de 13:30 a 15:30 horas)

- Continuación de las explicaciones sobre el tema sexto y presentación del primer caso práctico, aunque su realización puede no proceder hasta la explicación de los temas 7 y 8 inclusive.

\section{Séptima semana (del 29 de marzo al 1 de abril)}

Miércoles, día 31 de marzo (de 9 a 12:30 horas)

- Se inicia la explicación del tema séptimo sobre la tipología y modalidades del contrato de trabajo.

- Debe respetarse el tiempo de descanso.

\section{Viernes, día 1 de abril (de 13:30 a 15:30 horas)}

- Finalizan las explicaciones del tema 7 y se procede a abrir la actividad relativa a la realización del caso práctico si correspondiera su realización tras esta lección.

\section{Octava semana (del 5 al 9 de abril: Semana Santa)}

\section{Novena semana (del 12 al 16 de abril)}

\section{Miércoles, día 14 de abril (de 9 a 12:30 horas)}

- Comienzo de las explicaciones relativas al tema octavo y tras el descanso se presenta la primera actividad de simulación. La shocking news story debe estar accesible en el campus virtual y los grupos han de conformarse en la última parte de la clase. En esta ocasión el docente elige a los componentes de los equipos.

Viernes, día 16 de abril (de 13:30 a 15:30 horas)

- Se finaliza el tema relacionado con el modo de la prestación laboral y se habilita tiempo para resolver las dudas que haya generado la preparación de esta dramatización que se desarrollará el viernes siguiente.

\section{Décima semana (del 19 al 23 de abril)}

Miércoles, día 21 de abril (de 9 a 12:30 horas)

- Iniciamos las explicaciones relacionadas con el tiempo de la prestación de trabajo y se avanza en este tema porque en la siguiente sesión se destinará tiempo a la simulación.

\section{Viernes, día 23 de abril (de 13:30 a 15:30 horas)}

- Se comienza con la finalización de la explicación del tema nueve y se procede a desarrollar la simulación.

- Tras la simulación se presenta el segundo case of study para su resolución de forma individual. 


\section{Undécima semana (del 26 al 30 de abril)}

Miércoles, día 28 de abril (de 9 a 12:30 horas)

- La primera parte de esta sesión de clases se destina a la resolución de dudas referidas al bloque de temas que comprende las lecciones $6,7,8$ y 9 puesto que el viernes próximo tendrá lugar el segundo test.

- Se inician las explicaciones del tema décimo referido a la ordenación del salario.

Viernes, día 30 de abril (de 13:30 a 15:30 horas)

- Realización del test número dos (duración: 40 minutos y corrección del mismo)

- Tras el descanso de 10 minutos se retoman las explicaciones del tema décimo.

\section{Duodécima semana (del 3 al 7 de mayo)}

Miércoles, día 5 de mayo (de 9 a 12:30 horas)

- Comienzan las explicaciones del tema número 11 y tras el descanso se presenta la simulación relativa a la preliminary question que se desarrollará el miércoles próximo. Vuelven a formarse los grupos, si bien a elección de los alumnos.

\section{Viernes, día 7 de mayo (de 13:30 a 15:30 horas)}

- Continuación de la presentación relativa a las alteraciones y vicisitudes de la relación de trabajo y resolución de dudas en relación con la preparación de la simulación. Incidencia en las explicaciones atinentes a la temporalización de esta concreta actividad.

\section{Decimotercera semana (del 10 al 14 de mayo)}

Miércoles, día 12 de mayo (de 9 a 12:30 horas)

- Presentación de la simulación.

- Tras el descanso, se retoma la explicación teórica del duodécimo tema y se presenta el tercer caso práctico individual para su entrega en la décimo quinta semana.

Viernes, día 14 de mayo (de 13:30 a 15:30 horas)

- Finalización de la presentación de este tema.

\section{Decimocuarta semana (del 17 al 21 de mayo)}

Miércoles, día 19 de mayo (de 9 a 12:30 horas)

- La clase debe comenzar introduciendo a los alumnos en la última dinámica de interacción relativa, como se indicó, a la resolución autónoma y heterónoma de un conflicto colectivo en el que se alterarán los datos que el docente considere oportunos para evitar una total adhesión a las posturas ya existentes. El desarrollo por los discentes tendrá lugar el último miércoles de clase.

- Se dará inicio, además, a las explicaciones relacionadas con el tema número trece. 
Viernes, día 21 de mayo (de 13:30 a 15:30 horas)

- Finalización de las explicaciones sobre el tema número trece y continuación con las indicaciones y resolución de dudas para afrontar la tercera simulación.

\section{Decimoquinta semana (del 24 al 28 de mayo)}

Miércoles, día 26 de mayo (de 9 a 12:30 horas)

- Desarrollo de las explicaciones relativas al tema número catorce y aclaración de puntos finales antes de la realización de la simulación.

Viernes, día 28 de mayo (de 13:30 a 15:30 horas)

- Finalización del tema decimocuarto y planteamiento de dudas al respecto de la simulación y del desarrollo del último de los test que se celebrará el viernes último día de clase previsto.

\section{Decimosexta semana (del 31 de mayo al 4 de junio)}

Miércoles, día 2 de junio (de 9 a 12:30 horas)

- Inicio de la simulación: presentación de posturas con la intervención obligatoria de todos los alumnos participantes.

- Intervención de la comisión paritaria. Acercamiento de posturas y conclusión del conflicto si fuera posible.

- Intervención del mediador o árbitro para la resolución del conflicto correspondiente. De nuevo acercamiento de posturas. Conclusión del conflicto si fuera posible.

Viernes, día 4 de junio (de 13:30 a 15:30 horas)

- Desarrollo del tercer y último test (duración: 50 minutos). Corrección en clase.

- Presentación por el docente de las calificaciones finales a lo largo de la mañana y de forma virtual. Atención a las concretas peticiones o revisiones realizadas por los alumnos. 